\title{
From Gene to Behavior: L-Type Calcium Channel Mechanisms Underlying Neuropsychiatric Symptoms
}

\author{
Zeeba D. Kabir $^{1,2}$ • Arlene Martínez-Rivera ${ }^{1,2}$ - Anjali M. Rajadhyaksha ${ }^{1,2,3}$
}

Published online: 11 May 2017

(C) The American Society for Experimental NeuroTherapeutics, Inc. 2017

\begin{abstract}
The L-type calcium channels (LTCCs) $\mathrm{Ca}_{\mathrm{v}} 1.2$ and $\mathrm{Ca}_{\mathrm{v}} 1.3$, encoded by the CACNA1C and CACNA1D genes, respectively, are important regulators of calcium influx into cells and are critical for normal brain development and plasticity. In humans, CACNAIC has emerged as one of the most widely reproduced and prominent candidate risk genes for a range of neuropsychiatric disorders, including bipolar disorder (BD), schizophrenia (SCZ), major depressive disorder, autism spectrum disorder, and attention deficit hyperactivity disorder. Separately, CACNAID has been found to be associated with $\mathrm{BD}$ and autism spectrum disorder, as well as cocaine dependence, a comorbid feature associated with psychiatric disorders. Despite growing evidence of a significant link between CACNA1C and CACNA1D and psychiatric disorders, our understanding of the biological mechanisms by which these LTCCs mediate neuropsychiatric-associated endophenotypes, many of which are shared across the different disorders, remains rudimentary. Clinical studies with LTCC blockers testing their efficacy to alleviate symptoms associated with BD, SCZ, and drug dependence have provided mixed results, underscoring the importance of further exploring the neurobiological consequences of dysregulated $\mathrm{Ca}_{\mathrm{v}} 1.2$ and $\mathrm{Ca}_{\mathrm{v}} 1.3$. Here, we provide a review of clinical studies that have evaluated LTCC blockers for BD, SCZ, and
\end{abstract}

Z.D. Kabir and A. Martínez-Rivera contributed equally to this paper.

Anjali M. Rajadhyaksha amr2011@med.cornell.edu

1 Pediatric Neurology, Pediatrics, Weill Cornell Medicine, New York, NY, USA

2 Weill Cornell Autism Research Program, Weill Cornell Medicine, New York, NY, USA

3 Feil Family Brain and Mind Research Institute, Weill Cornell Medicine, New York, NY, USA drug dependence-associated symptoms, as well as rodent studies that have identified $\mathrm{Ca}_{\mathrm{v}} 1.2-$ and $\mathrm{Ca}_{\mathrm{v}} 1.3$-specific molecular and cellular cascades that underlie mood (anxiety, depression), social behavior, cognition, and addiction.

Keywords $\mathrm{Ca}_{\mathrm{v}} 1.2 \cdot \mathrm{Ca}_{\mathrm{v}} 1.3 \cdot C A C N A 1 C \cdot C A C N A 1 D$. Mood $\cdot$ Social $\cdot$ Addiction

\section{Introduction}

Over the last 2 decades, work from multiple laboratories has established that $\mathrm{Ca}_{\mathrm{v}} 1.2$ and $\mathrm{Ca}_{\mathrm{v}} 1.3 \mathrm{~L}$-type calcium channels (LTCCs) are critical mediators of experience-dependent plasticity in the brain. More recently these channels have been identified to be key for various neuronal processes that are essential for normal brain development, connectivity, and function [1-3]. This is further underscored by the discovery of neuropsychiatric risk genetic variants in CACNAIC, which codes for the $\mathrm{Ca}_{\mathrm{v}} 1.2 \propto 1$ subunit of LTCCs [4, 5], and CACNA1D, which codes for the $\mathrm{Ca}_{\mathrm{v}} 1.3 \propto 1$ subunit $[6,7]$. These variants can alter levels and function of the channels with consequences on neural processing and connectivity as revealed by human imaging studies $[1,8,9]$.

The LTCCs belong to the family of voltage-gated $\mathrm{Ca}^{2+}$ channels, with $\mathrm{Ca}_{\mathrm{v}} 1.2$ and $\mathrm{Ca}_{\mathrm{v}} 1.3$ being the primary LTCC subunits expressed in the brain [10]. Although there is considerable overlap in their expression pattern, as revealed by in situ hybridization (Table 1), Fos expression, a measure of neuronal activity [21], and studies with genetic mutant mice $([1,2]$ and as discussed below) have revealed differential contributions of these isoforms to neuronal function and behavior. These LTCC isoforms are present as heteromeric complexes with $\mathrm{Ca}_{\mathrm{v}} 1$ encoding the $\alpha 1$ pore-forming subunit that determines the physiological and pharmacological properties of these channels 
Table $1 \mathrm{Ca}_{\mathrm{v}} 1.2$ and $\mathrm{Ca}_{\mathrm{v}} 1.3$ mRNA expression within mesocorticolimbic brain regions in rodents

\begin{tabular}{|c|c|c|c|c|c|c|}
\hline & \multirow{2}{*}{ Brain region } & \multirow{2}{*}{$\mathrm{Ca}_{\mathrm{v}} 1.2 \mathrm{mRNA}$} & \multirow{2}{*}{$\mathrm{Ca}_{\mathrm{v}} 1.3$ mRNA Reference } \\
\hline & & & & & & \\
\hline Brain region & $\mathrm{Ca}_{\mathrm{v}} 1.2 \mathrm{mRNA}$ & $\mathrm{Ca}_{\mathrm{v}} 1.3 \mathrm{mRNA}$ & Reference & HI & $*$ & $* *$ \\
\hline $\begin{array}{l}\text { Hippocampus } \\
\text { CA1 }\end{array}$ & $*$ & $* *$ & {$[11]$} & OFC & $*$ & $* *$ \\
\hline
\end{tabular}

CA2

Dentate gyrus

Hippocampus Dentate gyrus

Amygdala

Hippocampus

CA1

CA3

Dentate gyrus

Hippocampus

Dentate gyrus

Amygdala

VTA

NAc

Core

Shell

Hippocampus

CA

Dentate gyrus

VTA

PFC

Hippocampus

CA1

CA3

Dentate gyrus

Amygdala

BLA

Hippocampus

CA1

CA3

Dentate gyrus

Hippocampus

Hippocampal formation

Hippocampus

CA1

CA3

Dentate gyrus

Amygdala

$\mathrm{CeA}$

MeA

BLA

NAc

Core

Shell

PFC

Cing

PreL

*** $\quad * *$

$* * * \quad * *$

$* * * \quad * * *$

** $\quad * *$

* $\quad *$

NR

NR

$\mathrm{NR} \quad * * *$

$* *$

**

*** NR

** NR

* $\quad * * *$

$\begin{array}{ll}* & * * \\ * * & * * *\end{array}$

$* *$

$* * *$

$* * *$

$* * *$

$* * *$

$*$

** $\quad * *$

$* * \quad *$

*** $\quad *$

$* * * \quad *$

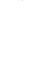

** $\quad *$

$* \quad * *$

$* * * \quad * *$

$* * * \quad * * *$

*** NR

** $\quad * *$

$* * \quad * *$

$* * \quad * * *$

$* * *$

$* *$

**

$* *$

$*$

$*$

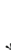

$*$

$* *$

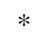

$* *$

Comparison of $\mathrm{Ca}_{\mathrm{v}} 1.2$ and $\mathrm{Ca}_{\mathrm{v}} 1.3$ mRNA levels are made within and across brain regions for each study and not across different studies

$\mathrm{NR}=$ not reported $; \mathrm{VTA}=$ ventral tegmental area; NAc $=$ nucleus accum bens; $\mathrm{CA}$ = hippocampal comus ammon regions $\mathrm{CA} 1, \mathrm{CA} 2$, and $\mathrm{CA} 3$; $\mathrm{PFC}=$ prefrontal cortex; $\mathrm{BLA}=$ basolateral amygdala; $\mathrm{CeA}=$ central amygdala; $\mathrm{MeA}=$ medial amygdala , Cing $=$ cingulate cortex PreL = prelimbic cortex; IL = infralimbic cortex; $\mathrm{OFC}=$ orbitofrontal cortex

*Low expression, **moderate, or ***strong expression

$[2,22]$. The $\mathrm{Ca}_{\mathrm{v}} 1.2$ and $\mathrm{Ca}_{\mathrm{v}} 1.3$ subunits share a high degree of sequence and structural similarity resulting in lack of selectivity of LTCC pharmacological activators and blockers [2]. However, as we now know, $\mathrm{Ca}_{\mathrm{v}} 1.2$ and $\mathrm{Ca}_{\mathrm{v}} 1.3$ have different physiological characteristics [23-25] and associate with different proteins to form unique subunit-specific signaling complexes at the neuronal membrane [26-28], resulting in differential contributions to neuronal function and neuropathology underlying disease.

In this review we will first provide an overview of $C A C N A 1 C$ and $C A C N A 1 D$ genetic risk variants linked to neuropsychiatric disorders. As recent genetic findings have raised great interest in targeting LTCCs as a potential strategy for the treatment of neuropsychiatric disorders and drug dependence, as well as repurposing current clinically used LTCC medications $[2,6,29,30]$, we will next review clinical studies performed to date with LTCC blockers. We will then provide an overview of our current knowledge of the brain-regionspecific contribution of $\mathrm{Ca}_{\mathrm{v}} 1.2$ and $\mathrm{Ca}_{\mathrm{v}} 1.3$ channels to neural and molecular mechanisms underlying the pathophysiology of neuropsychiatric and neurodevelopmental-associated behavioral endophenotypes, obtained using preclinical animal models (Fig. 1). Given the complex nature of neuropsychiatric disorders, we believe that understanding biological phenotypes in the context of behavioral endophenotypes, will greatly help both in better understanding neuropathology, as well as provide a framework for exploring new therapeutic targets for $C A C N A 1 C$ - and CACNAID-associated disorders.

\section{Functional Impact of $C A C N A 1 C$ and $C A C N A 1 D$ Genetic Risk Variants}

As recently reviewed in detail in Heyes et al. [5], genome-wide association studies have identified multiple single nucleotide polymorphisms (SNPs) in CACNA1C to be significantly associated with bipolar disorder (BD) [31] and schizophrenia (SCZ) [32]. Additionally, risk SNPs within CACNAIC have also been linked to major depressive disorder (MDD) [33], autism 
Fig. $1 \mathrm{Ca}_{\mathrm{v}} 1.2$ - and $\mathrm{Ca}_{\mathrm{v}} 1.3$ mediated anatomical and molecular pathways underlying the endophenotypes associated with neuropsychiatric disorders. Solid lines indicate pathways that have been identified for the respective behavioral endophenotypes and dotted lines indicate potential pathways that may be recruited AMPAR $=\alpha$ amino-3-hydroxy-5-methyl-4isoxazolepropionic acid receptors; $\mathrm{PFC}=$ prefrontal cortex; HPC = hippocampus; $\mathrm{NAc}=$ nucleus accumbens; VTA = ventral tegmental area; REDD1 $=$ regulated in development and DNA damage response 1; CPAMPAR $=\mathrm{Ca}^{2+}$-permeable AMPAR; ERK2 = extracellular regulated kinase 2 ; $\mathrm{CaMKII}=$ CaM-dependent protein kinase II

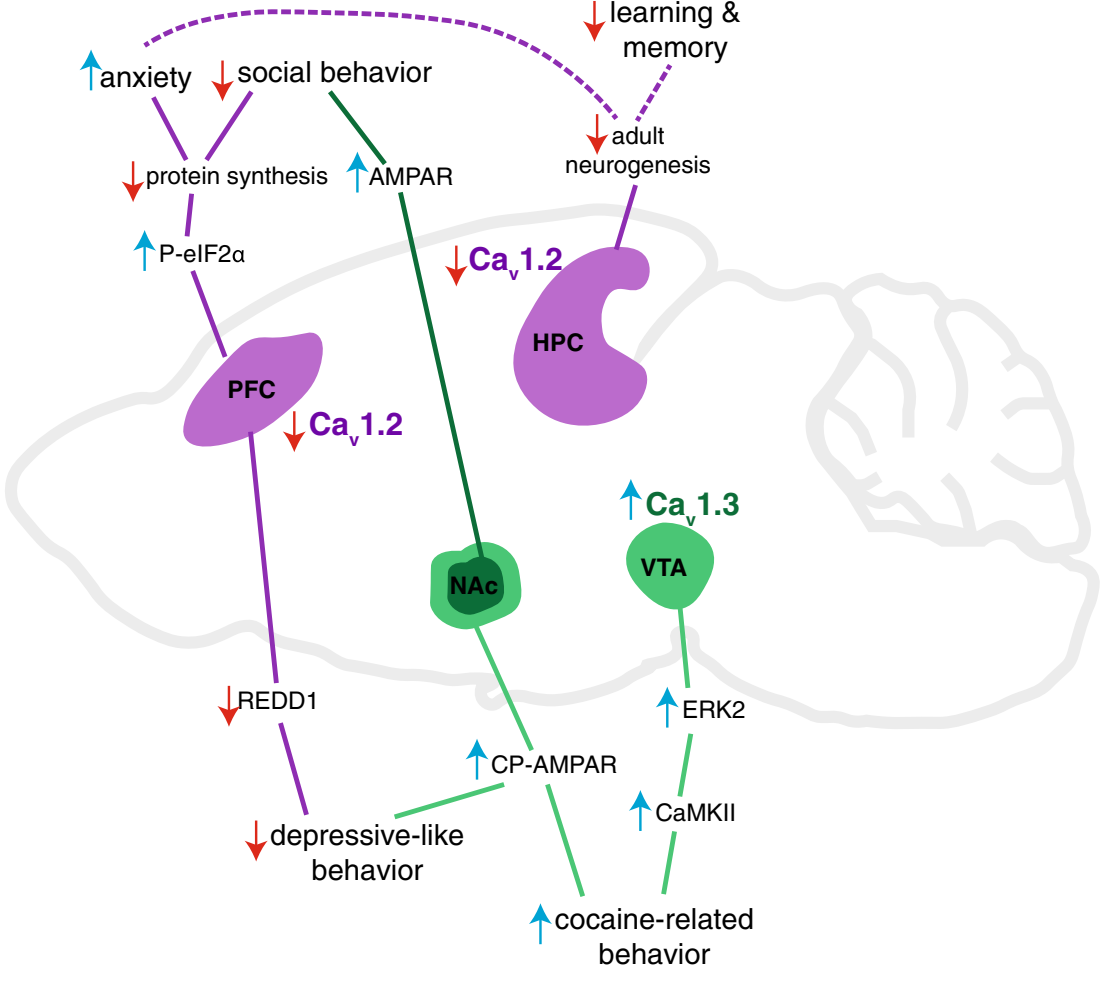

spectrum disorder (ASD) [34], and attention deficit hyperactivity disorder (ADHD) [35]. Furthermore, a meta-analysis study has linked disease-associated CACNA1C SNPs to all the abovementioned 5 disorders [35]. The majority of these SNPs are present in the intronic, $5^{\prime}$ or $3^{\prime}$ untranslated regions of CACNA1C $[4,5]$, in accordance with the growing body of literature establishing that large numbers of SNPs associated with complex diseases such as neuropsychiatric disorders, are present within noncoding regions [36]. Most of the CACNA1C risk SNPs associated with SCZ and BP, particularly SNP rs1006737 and those in linkage disequilibrium, are present in a large intron between exons 3 and 4 [5]. Functional studies to evaluate the impact of risk SNPs on gene expression are beginning to establish that these SNPs lie within regions that are under tight transcriptional control, with risk SNPs being able to alter gene expression by differentially binding nuclear proteins and also altering long-range intronic enhancer and promoter interactions within $C A C N A 1 C$ [37, 38]. Biological studies to measure levels of $C A C N A 1 C$ have found both increased [38-40] and decreased [37, 38, 40, 41] expression of CACNA1C, depending on the brain region and cellular system examined. This suggests that transcriptional control of CACNA1C is highly complex and most likely, differentially controlled at the level of brain region and cell type. Nevertheless, these studies demonstrate that intronic $C A C N A 1 C$ risk SNPs can alter levels of CACNAIC and that loss or gain of $\mathrm{Ca}_{\mathrm{v}} 1.2$ can contribute to disease symptoms.

In addition to the noncoding variants, 2 truncating mutations in CACNA1C have been identified in a whole-exome sequencing study of SCZ that are predicted to cause loss of function [42], though this remains to be confirmed. As discussed in Heyes et al. [5], these truncation mutations in CACNAIC could exert a dominant negative effect through the interaction of truncated mutant proteins with the $\mathrm{Ca}_{\mathrm{v}} 1.2$ channel, as has been reported for other voltage-gated subunits [43-45].

A coding CACNAIC variant has also been linked to ASD. A gain-of-function mutation in $\mathrm{Ca}_{\mathrm{v}} 1.2$ causes Timothy syndrome (TS), an autosomal dominant developmental disorder [46]. This syndrome is a multiorgan disorder associated with malformations, cardiac symptoms (long QT), and neurological developmental defects [46-48], including manifestation of neuropsychiatric phenotypes [48]. The mutation in $\mathrm{Ca}_{\mathrm{v}} 1.2$ that causes TS is a sporadic, dominant glycine-to-arginine mutation that is located at position 406 (G406R) in a mutually exclusive, alternatively spliced exon 8 or $8 \mathrm{~A}$ of $C A C N A 1 C$ [46]. G406R in exon 8a causes TS1 and G406R or G402S in exon 8 causes a rare variant of TS, namely TS2 [46, 48]. TS1 has been associated with ASD [46, 48], whereas patients with TS2 additionally manifest with neuropsychiatric conditions [41, 48]. One patient with TS2 was reported to exhibit obsessive compulsive disorder and depression [48], while another patient with TS2 who carried the G402S mutation developed BD in adulthood [41].

Similar to $C A C N A 1 C$, genetic variants in CACNA1D have also been identified in neuropsychiatric disorders. A SNP in CACNA1D (rs893363), which codes for $\mathrm{Ca}_{\mathrm{v}} 1.3$, has been associated in the 5-disorder gene analysis, including BD, SCZ, ADHD, MDD, and ASD [35]. Separately noncoding variants [31] and 2 coding variants (A1751P and R1771W) have been 
linked to BD [49]. However, a study in the Han Chinese population found no significant SNPs in CACNAID associated with SCZ [50]. SNPs in CACNA1D have also been associated with cocaine dependence [51]. Furthermore, whole-exome sequencing studies have identified 2 de novo mutations (p.A749G and p.G407R) in CACNA1D in patients with sporadic autism and intellectual disability $[52,53]$. Functional studies have identified these mutations as gain-of-function of $\mathrm{Ca}_{\mathrm{v}} 1.3$ LTCCs [7, 54].

Thus, based on the above findings on the impact of CACNAIC and CACNA1D disease-associated genetic variants on gene expression and channel function, the available data suggest that higher or lower levels of $\mathrm{Ca}^{2+}$ influx in neurons can be detrimental. In addition, LTCCs can also regulate neuronal firing. For example, LTCCs can directly provide a depolarizing stimulus; this can stabilize upstates/plateau potentials (e.g. [55]), thus affecting neuronal firing. LTCCs can also couple to $\mathrm{Ca}^{2+}$-activated $\mathrm{K}$ channels $[56,57]$, thus moderating neuronal firing. Therefore, decreased LTCC activity could actually increase firing in some neurons, which may trigger $\mathrm{Ca}^{2+}$ influx through other sources (other voltagegated $\mathrm{Ca}^{2+}$ channels subtypes or glutamate $N$-methyl-D-aspartate receptors). Similarly, increase in LTCC activity as a result of gain of LTCC function could silence neurons. Thus, altered $\mathrm{Ca}_{\mathrm{v}} 1.2$ and $\mathrm{Ca}_{\mathrm{v}} 1.3$ LTCC levels or activity, in a cell-typespecific manner, can affect neuronal function in multiple ways that could negatively affect brain function and contribute to neuropsychiatric symptoms in disorders associated with CACNAIC and CACNAID.

\section{Targeting L-Type Calcium Channels in the Treatment of Neuropsychiatric Disorders and Drug Dependence}

LTCC blockers have been used clinically for several decades in the treatment of cardiac conditions such as hypertension, arrhythmias, and cardiac ischemia [2]. Recently, with growing evidence of the association between LTCC genes and neuropsychiatric disorders [5], there has been increased interest in repurposing these drugs for the treatment of neuropsychiatric conditions and drug dependence [6, 29]. Since the 1980s several clinical studies have examined the efficacy of LTCC blockers using the 3 classes of LTCC pharmacological blockers - dihydropyridines (DHPs; nifedipine, amlodipine, felodipine, isradipine, nicardipine, nisoldipine, and nimodipine); phenylalkylamines (verapamil); and benzothiazepines (diltiazem) - to alleviate symptoms in patients presenting with neuropsychiatric conditions and drug dependence. Below, we review the findings of these studies (see Table 2). Of note, many of these clinical studies have utilized high systemic doses of LTCC blockers, particularly the DHPs and thus could have significant confounding effects on behavior, as demonstrated by rodent studies [105, 106].
Additionally, several of these studies have used the phenylalkylamine blocker, verapamil (Table 2). In addition to verapamil's nonspecific effects such as blocking other $\mathrm{Ca}^{2+}$ channels [107], potassium channels [108-110], and $\alpha$ adrenergic receptors [111], studies examining how well verapamil enters the brain in humans have been sparse. Verapamil is a substrate for P-glycoprotein (P-gp) substrate, an efflux transporter found in several organs, including the blood-brain barrier, where it plays an important role for the entry of drugs, including verapamil, into the brain [112]. Verapamil can function as a stimulator of the P-gp activity at low concentrations, preventing brain entry, whereas at high concentrations it acts as an inhibitor of P-gp, allowing brain entry [113, 114]. However, verapamil at high concentrations, although capable of penetrating the bloodbrain barrier, can have toxics effects [115].

\section{BD}

The efficacy of the LTCC blocker verapamil in alleviating acute mania observed in BD has been explored in several studies [116]. While some studies report a significant decrease in the severity of mania in patients with BD or manic patients $[58$, 59, 62-66, 68, 69], several others report no antimanic effects when verapamil was administered as a monotherapy $[60,61$, 70-72]. However, when verapamil was administered in combination with the mood stabilizer lithium to patients with BD who were unresponsive to lithium [70] or in conjunction with the antipsychotic medication chlorpromazine [60] there was significant improvement in manic symptoms. This suggests that verapamil could have some potential for maintenance therapy of mania but only when administered in combination with other drugs. In addition to these findings, verapamil was found to improve significantly major psychotic depressive symptoms in 1 patient [67] and improve depressive symptom scores in patients prescribed verapamil for hypertension [73].

Although there are only a handful of studies with nimodipine and diltiazem, the findings are more consistent, though not as thoroughly investigated as verapamil. Bipolar manic patients treated with nimodipine either as a monotherapy [74-76] or in combination with lithium [77] or the antiseizure medication carbamazepine [74] showed significant improvements. Similar improvements in mood were reported when an adolescent with refractory, ultradian rapid cycling $\mathrm{BD}$ was treated with nimodipine [78]. Likewise, both bipolar manic patients [79] and treatment-resistant bipolar patients [80] treated with diltiazem had significantly decreased manic symptoms. However, in patients with no prior psychiatric history, the use of nifedipine to treat angina was associated with the onset of depression [81].

\section{SCZ}

Verapamil has also been tested in patients with SCZ. In patients with acute $\mathrm{SCZ}$, verapamil treatment when administered 
Table 2 Type of clinical study using L-type calcium channel blockers in neuropsychiatric disease

\begin{tabular}{|c|c|c|c|}
\hline $\begin{array}{l}\text { Neuropsychiatric disease } \\
\text { treated }\end{array}$ & $\begin{array}{l}\text { L-type calcium } \\
\text { channel } \\
\text { blocker used }\end{array}$ & Type of clinical study performed & Reference(s) \\
\hline \multirow[t]{14}{*}{ Bipolar disorder } & \multirow[t]{8}{*}{ Verapamil } & Nonrandomized & [58-61] \\
\hline & & $\begin{array}{l}\text { Randomized; patients received either verapamil or lithium and efficacy } \\
\text { compared }\end{array}$ & {$[62]$} \\
\hline & & $\begin{array}{l}\text { Randomized: crossover study; patients received either verapamil or lithium and } \\
\text { then treatment switched }\end{array}$ & {$[63]$} \\
\hline & & Case report & {$[64-67]$} \\
\hline & & Randomized placebo-controlled within subject & {$[68]$} \\
\hline & & Nonrandomized placebo within subjects & [69] \\
\hline & & $\begin{array}{l}\text { Randomized: phase I—lithium, phase II—nonresponders (verapamil or } \\
\text { lithium); } \\
\text { phase III—nonresponders (combined verapamil/lithium) } \\
\text { Randomized placebo }\end{array}$ & {$[71,72]$} \\
\hline & & $\begin{array}{l}\text { Randomized; patients received verapamil or the antihypertensive drug atenolol } \\
\text { and } \\
\text { efficacy compared }\end{array}$ & {$[73]$} \\
\hline & \multirow[t]{4}{*}{ Nimodipine } & Randomized placebo-controlled within-subjects & {$[74]$} \\
\hline & & Nonrandomized placebo within-subject & {$[75]$} \\
\hline & & Nonrandomized & {$[76]$} \\
\hline & & Case report & {$[77,78]$} \\
\hline & Diltiazem & Nonrandomized & {$[79,80]$} \\
\hline & Nifedipine & Case report & {$[81]$} \\
\hline \multirow[t]{7}{*}{ Schizophrenia } & \multirow[t]{5}{*}{ Verapamil } & Case report & {$[82]$} \\
\hline & & Randomized placebo & {$[83,84]$} \\
\hline & & Randomized placebo-controlled within subject & {$[85]$} \\
\hline & & Nonrandomized & {$[86]$} \\
\hline & & Nonrandomized placebo within subject & {$[87,88]$} \\
\hline & \multirow[t]{2}{*}{ Nifedipine } & Nonrandomized & {$[89]$} \\
\hline & & Randomized placebo & {$[90]$} \\
\hline \multirow[t]{6}{*}{ Cocaine dependence } & Nimodipine & Randomized placebo-controlled within subject & {$[91]$} \\
\hline & Isradipine & Randomized placebo-controlled within subject & {$[92,93]$} \\
\hline & Nimodipine & Randomized placebo & {$[94]$} \\
\hline & Nifedipine & Randomized placebo-controlled within subject & {$[95]$} \\
\hline & Amlodipine & Nonrandomized & {$[96]$} \\
\hline & Isradipine & Randomized placebo-controlled within subject & {$[97]$} \\
\hline \multirow[t]{3}{*}{ Morphine dependence } & Verapamil & Randomized placebo & {$[98]$} \\
\hline & $\begin{array}{l}\text { Diltiazem, verapamil, } \\
\text { nimodipine }\end{array}$ & Randomized placebo-controlled within subject & [99] \\
\hline & Nifedipine & $\begin{array}{l}\text { Randomized; patients received nifedipine or the } \alpha \text {-adrenoceptor blocker, clo- } \\
\text { nidine; } \\
\text { only nifedipine effects reported }\end{array}$ & {$[100]$} \\
\hline \multirow[t]{4}{*}{ Alcohol dependence } & $\begin{array}{l}\text { Verapamil, } \\
\text { nimodipine }\end{array}$ & Randomized placebo & {$[101]$} \\
\hline & Isradipine & $\begin{array}{l}\text { Quasirandom placebo within subject; patients received } 9 \text { different combinations } \\
\text { of } \\
\text { ethanol or isradipine at different doses; only the first and second treatment } \\
\text { was not randomly given }\end{array}$ & {$[102]$} \\
\hline & Verapamil, nifedipine & Randomized placebo-controlled within subject & {$[103]$} \\
\hline & Nimodipine & Nonrandomized & {$[104]$} \\
\hline
\end{tabular}

as a monotherapy resulted in a significant decrease in psychotic symptoms [82]. These findings were confirmed in a separate study that reported a similar small, but significant, attenuation of psychotic symptoms with verapamil [83]. Similarly, patients with chronic SCZ treated with verapamil for 28 days displayed significant improvements in positive 
and negative symptoms, as well as in anxiety and depression [86]. In contrast to these findings, other studies have reported an increase in paranoia in verapamil-treated patients with chronic schizophrenia who were recently withdrawn from neuroleptics [87], or no effect on the psychological state [88] and negative symptoms [84]. Similar to the results with verapamil, the effects of nifedipine on alleviating the psychotic symptoms are conflicting. While some studies showed that patients with chronic schizophrenia receiving nifedipine showed an improvement on the Dementia Scale [85] and the Brief Psychiatric Rating Scale [89], another showed no improvements based on the Psychiatric Symptom Assessment Scale ratings [90].

\section{Cocaine Dependence}

Evidence from rodent studies has identified an important role of LTCCs in multiple aspects of cocaine addiction, making these channels a potential target for the treatment of addiction. Over the last few decades, clinical studies have tested the efficacy of LTCC blockers on the subjective effects of cocaine, though the results have been mixed. While some studies report no effect with isradipine and nimodipine [91, 92], others have reported a reduction in the subjective response to cocaine with nifedipine [95]. In contrast, a recent study reported enhanced subjective effects with isradipine [93]. The effects of LTCCs have also been tested on cocaine craving, the primary cause of relapse to cocaine use, with nimodipine [94], amlodipine [96], and isradipine [97] reducing cocaine craving.

\section{Morphine Dependence}

The impact of LTCC blockers on the subjective effects of morphine are mixed. While 1 study reported a reduction in the subjective effect of morphine with verapamil [98], another study showed no influence of nimodipine, verapamil, and diltiazem on counteracting morphine's subjective effects in healthy humans [99]. Separately, it has been reported that nifedipine treatment caused confusion in individuals that were in morphine withdrawal [100]. These studies suggest that LTCC blockers may show selective effects in morphinedependent individuals, having beneficial effects in some but detrimental effects in others.

\section{Alcohol Dependence}

With ethanol, LTCC blockers nimodipine and verapamil have been reported to have no effect on the subjective and psychomotor effects of the drug [101]. Similarly, isradipine had no effect on ethanol's acute effects on poor psychomotor performance [102], and failed to antagonize ethanol intoxication
[103]. However, nimodipine has been found to be effective for the treatment of ethanol's withdrawal symptoms [104].

The discrepancies in the effects of LTCC blockers in the treatment of psychiatric disorder-associated symptoms and on the symptoms associated with drug dependence, as reviewed above, may be a consequence of a myriad of factors, including the high doses used; however, it highlights the complexity of neuropsychiatric disorders, as well as how dysregulated LTCCs may influence different psychiatric symptoms. Given our current knowledge of the varying impact of disease-risk variants to $C A C N A 1 C$ and $C A C N A 1 D$ levels (increase or decrease) and $\mathrm{Ca}_{\mathrm{v}} 1.2$ and $\mathrm{Ca}_{\mathrm{v}} 1.3$ function (gain or loss), it is not surprising that LTCC blockers may be efficacious in some individuals but not all and for some symptoms and not all those seen in CACNA1C and CACNA1D-linked neuropsychiatric conditions. Thus, understanding how $\mathrm{Ca}_{\mathrm{v}} 1.2$ and $\mathrm{Ca}_{\mathrm{v}} 1.3$ channel mechanisms contribute to neuropsychiatric-related symptoms can be greatly helpful. As progress on the development of new therapeutics for psychiatric disorders has been slow, understanding biological pathways in the context of disease symtoms (e.g., anxiety, social, depression, cognition) are key in identifying new targets for developing medications. We believe that this is particularly important given the complex nature of neuropsychiatric disorders versus the idea that they are sole entities as previously considered.

\section{L-Type Calcium Channel Signaling in Neurons and Relevance to Neuropsychiatric Disorders}

Several lines of evidence from both human and animal studies have unequivocally established a critical contribution of $\mathrm{Ca}^{2+}$ signaling pathways to the pathophysiology of both neuropsychiatric and neurodevelopmental disorder $[1,6,117] . \mathrm{Ca}_{\mathrm{v}} 1.2$ and $\mathrm{Ca}_{\mathrm{v}} 1.3$ channels are key mediators of $\mathrm{Ca}^{2+}$ signaling in neurons [26]. In vitro studies have established that depolarization-induced increase in local $\mathrm{Ca}^{2+}$ activates the calcium sensor calmodulin $(\mathrm{CaM})$ at the synapse that subsequently activates a series of $\mathrm{Ca}^{2+} / \mathrm{CaM}$-dependent protein kinases (CaMKs) [118-122] and also the Ras/mitogen-activated protein kinase (MAPK) pathway [123-125], both of which transduce molecular cascades to the nucleus, activating gene expression via the extensively studied transcriptional factor cAMP response element-binding protein (CREB) (Fig. 2). CREB-activated genes are critically involved in synaptic, neuronal, and behavioral plasticity [126-130]. LTCC-induced kinase pathways are also recruited for phosphorylation of signaling molecules that activate other transcription regulators, including myocyte enhancer factor-2 [131-134] and MeCP2 (Fig. 2), key factors involved in neuronal development, behavioral alterations, and neurodevelopmental disorders. In addition to activation of the kinase pathways, LTCCs can also activate the phosphatase pathway that likewise modulates 


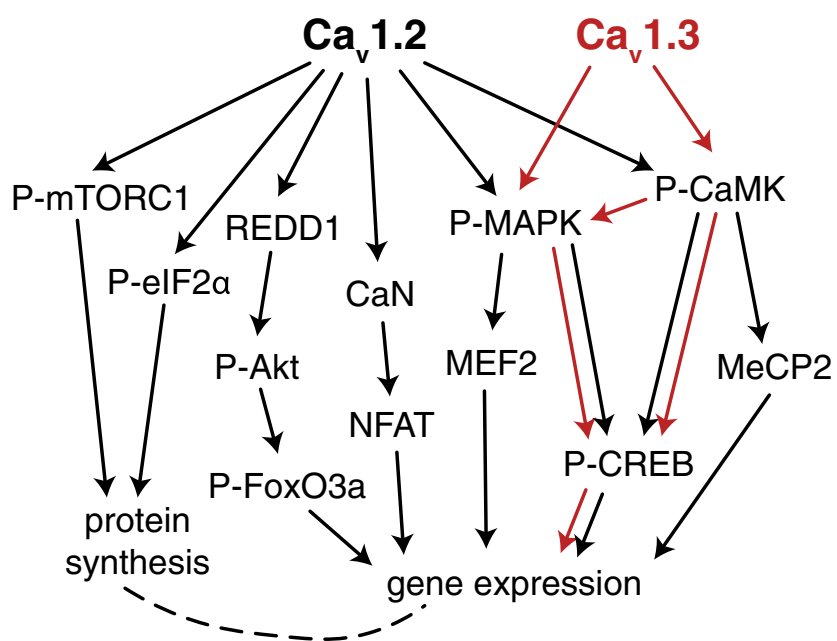

Fig. $2 \mathrm{Ca}_{\mathrm{v}} 1.2$ and $\mathrm{Ca}_{\mathrm{v}} 1.3$ signaling mechanisms. Solid lines indicate pathways that have been directly linked to $\mathrm{Ca}_{\mathrm{v}} 1.2$ or $\mathrm{Ca}_{\mathrm{v}} 1.3$ channels and dotted line indicates potential pathway that may be recruited. Black arrows indicate $\mathrm{Ca}_{\mathrm{v}} 1.2$-specific pathways; red arrows indicate $\mathrm{Ca}_{\mathrm{v}} 1.3$ specific pathways. mTORC $1=$ mammalian target of rapamycin complex 1; REDD1 = regulated in development and DNA damage response $1 ; \mathrm{P}-\mathrm{MAPK}=$ phosphorylated mitogen-activated protein kinase; $\mathrm{P}-\mathrm{CaMK}=$ phosphorylated CAM-dependent protein kinase; $\mathrm{P}$-eIF $2 \alpha=$ phosphorylated eukaryotic initiation factor 2 alpha; $\mathrm{CaN}=$ calcineurin; $\mathrm{P}$ $\mathrm{Akt}=$ phosphorylated protein kinase $\mathrm{B} ; \mathrm{MEF} 2=$ myocyte enhancer factor 2 ; NFAT $=$ nuclear factor of activated T cells; $\mathrm{P}-\mathrm{CREB}=$ phosphorylated cAMP response element-binding protein

transcription factor function. This includes the nuclear factor of activated T cells (NFAT) family of transcription factors that is regulated by the LTCC-activated $\mathrm{Ca}^{2+}$-calmodulin-dependent phosphatase calcineurin that dephosphorylates NFAT cytoplasmic 3 [135] and NFAT cytoplasmic 4 [136], inducing its translocation from the cytoplasm to the nucleus to regulate gene expression. Alteration of myocyte enhancer factor-2 and NFAT, as well as CREB signaling networks, has been linked to dendritic retraction as a consequence of elevated $\mathrm{Ca}^{2+}$ in induced pluripotent cells from patients with TS [132].

The significance of these LTCC-activated pathways to neuropsychiatric disease pathology is underscored by several pathway network analyses that have repeatedly identified significant association of the calcium signaling pathway to BD [137, 138], SCZ [138, 139], MDD [138], and ASD [140], highlighting the calcium pathway as a common dysregulated mechanism underlying the etiology of these disorders. This has also been observed using proteomic approaches with postsynaptic density fractions from the cortex of patients with SCZ [141] and BD [142] that have identified altered levels of proteins that are mediators of calcium signaling. Additionally, pathway analyses have identified significant enrichment of the MAPK/extracellular regulated kinase (ERK) pathway in ASD [140, 143], SCZ [141], and depression [144], and whole-exome sequencing has found rare and likely protein-damaging mutations in members of the MAPK/ ERK and CREB-regulated intracellular signaling pathways in patients with $\mathrm{BD}$ [145]. Another pathway enriched in the proteomics-based pathway analysis from the postsynaptic density of patients with BD was the eukaryotic initiation factor $2 \alpha$ (eIF $2 \alpha$ ) signaling pathway [142], which is involved in mRNA translation [146] and a pathway we review below as a new candidate pathway linked to behavioral deficits in $\mathrm{Ca}_{\mathrm{v}}$ 1.2-deficient mice. In light of these findings, it is evident that dysregulation in LTCC and $\mathrm{Ca}^{2+}$ signaling can result in neuronal alterations that contribute to the pathogenesis of neuropsychiatric-related cellular [51, 147-150], physiological, synaptic $[150,151]$, and behavioral phenotypes [51, $150,152,153]$, all of which we discuss below.

\section{L-Type $\mathrm{Ca}^{2+}$ Channels and Neuropsychiatric-Related Phenotypes: Preclinical Animal Studies}

Rodents have proved to be a useful tool to study human disease-related behavioral symptoms. Given the predominance of noncoding variants in $C A C N A 1 C$ that are predicted to affect transcriptional control and result in lower or higher levels of CACNA1C, studying gene knockout and overexpressing mice can be highly useful. Similarly, mice harboring coding mutations that cause either loss or gain of function can be informative. The $\mathrm{Ca}_{\mathrm{v}} 1.2$ and $\mathrm{Ca}_{\mathrm{v}} 1.3 \mathrm{LTCC}$ isoforms have structural similarities making them both equally sensitive to LTCC pharmacological agents [154], posing a challenge to study isoformspecific brain and behavioral alterations. To overcome this, several different laboratories have developed genetic mutant mouse models that have altered expression or function of either $\mathrm{Ca}_{\mathrm{v}} 1.2$ or $\mathrm{Ca}_{\mathrm{v}} 1.3$. The most common models used to study $\mathrm{Ca}_{\mathrm{v}} 1.2$-specific mechanisms have been the heterozygous constitutive knockout mouse model (homozygous is embryonic lethal [155]), and temporal, spatial, and cell-type-specific conditional mouse models with restricted knockdown of cacnalc (encoding $\mathrm{Ca}_{\mathrm{v}} 1.2$ ) in the brain using Cre-recombinase specific drivers (mouse lines and viral vectors). Constitutive $\mathrm{Ca}_{\mathrm{v}} 1.2$ heterozygous knockout mice develop a cardiac phenotype, particularly following stress [156]; however, it is unlikely that this cardiac phenotype affects brain phenotypes at baseline [153, 157] or following stress [158]. For $\mathrm{Ca}_{\mathrm{v}} 1.3$ studies, there exists the $\mathrm{Ca}_{\mathrm{v}} 1.3$ knockout mouse, though because of the high expression of $\mathrm{Ca}_{\mathrm{v}} 1.3$ in the hair cells of the ear are deaf and limit their use for behavioral studies. To overcome this and the lack of subunit-specific pharmacological agents, the Striessnig laboratory developed a $\mathrm{Ca}_{\mathrm{v}} 1.2 \mathrm{DHP}$-insensitive $\left(\mathrm{Ca}_{\mathrm{v}} 1.2 \mathrm{DHP}^{-/-}\right)$ mouse that harbors a single point mutation in the $\mathrm{Ca}_{\mathrm{v}} 1.2 \alpha 1$ subunit at the DHP binding site, rendering $\mathrm{Ca}_{\mathrm{v}} 1.2$ channels insensitive to DHPs [159], allowing the specific pharmacological manipulation of $\mathrm{Ca}_{\mathrm{v}} 1.3$ channels $[21,51,159-161]$. Below we review studies that have utilized these preclinical mouse 
models to examine behavioral and molecular phenotypes related to neuropsychiatric disorders.

\section{$\mathrm{Ca}_{\mathbf{v}} 1.2$ Channel Mechanisms and Neuropsychiatric-Related Endophenotypes}

\section{Anxiety}

Symptoms of anxiety are one of the most prevalent endophenotypes of psychiatric disorders [162]. In mice with a $50 \%$ reduction of cacnalc $\left(\mathrm{Ca}_{\mathrm{v}} 1.2 ; \mathrm{Ca}_{\mathrm{v}} 1.2\right.$ heterozygous mice), both females [153, 157] and males [153] display anxiety-like behavior. Similarly, restricted elimination of cacnalc $\left(\mathrm{Ca}_{\mathrm{v}} 1.2\right)$ in excitatory glutamatergic neurons of the forebrain (forebrain $\mathrm{Ca}_{\mathrm{v}} 1.2$ conditional knockout mice), a cell type with high expression of $\mathrm{Ca}_{\mathrm{v}} 1.2$, as well as selective elimination of $\mathrm{Ca}_{\mathrm{v}} 1.2$ in the adult prefrontal cortex (PFC) has been found to result in anxiety-like behavior $[150,153]$.

These preclinical findings are supported by clinical studies that have identified generalized anxiety $[163,164]$ and trait anxiety [165] in CACNA1C risk allele (rs1006737) carriers together with structural [166] and functional alterations in the PFC of these individuals [167]. In contrast, male mice harboring the TS gain-of-function $\mathrm{Ca}_{\mathrm{v}} 1.2$ mutation display no anxiety-like phenotype [168], suggesting that a loss, rather than a gain, of $\mathrm{Ca}_{\mathrm{v}} 1.2$ function may mediate anxiety-like behavior.

\section{Social Behavior}

Impairments in social behavior are observed in a range of neuropsychiatric disorders [169] and represent a core domain in ASD [170]. Using rodents studies, it has become evident that dysregulated $\mathrm{Ca}^{2+}$ as a consequence of altered $\mathrm{Ca}_{\mathrm{v}} 1.2$ channel function can influence social behavior [168]. The TS $\mathrm{Ca}_{\mathrm{v}} 1.2$ gain-of-function mouse model displays a significant social deficit [168], demonstrating that excess $\mathrm{Ca}^{2+}$ can adversely affect social behavior. Similarly, mice with restricted deletion of $\mathrm{Ca}_{\mathrm{v}} 1.2$ in glutamatergic neurons of the forebrain display a similar deficit in social behavior [150]. Focal knockdown of $\mathrm{Ca}_{\mathrm{v}} 1.2$ in the adult PFC is sufficient to induce the social behavioral deficits [150], identifying the PFC as the common anatomical structure of $\mathrm{Ca}_{\mathrm{v}} 1.2$ 's effects on social function and anxiety-like behavior (Fig. 1). This is not surprising given that anxiety has been shown to negatively impact social function [171-173].

As loss of $\mathrm{Ca}_{\mathrm{v}} 1.2$ results in both anxiety and social behavioral deficits, work from our laboratory has begun to dissect the mechanistic interaction between anxiety and social function by examining the biological pathways underlying these impairments. One mechanism that has received tremendous attention in recent years is dysregulation of dendritic mRNA translation and protein synthesis, being attributed to behavioral impairments. The role of LTCCs in regulating dendritic mRNA translation versus nuclear transcription remains largely unknown. One in vitro study has linked LTCCs to the mammalian target of rapamycin (mTOR) pathway [174], one of the most highly studied pathways regulating mRNA translation and protein synthesis [175]. In support of this, loss of $\mathrm{Ca}_{\mathrm{v}} 1.2$ in glutamatergic neurons of the forebrain results in a significant decrease in levels of general protein synthesis in the PFC [150] (Figs. 1 and 2). Molecular studies have identified lower phosphorylated (at serine S2448) mTOR, indicating lower activity of mTOR complex 1 (mTORC1). In parallel, $\mathrm{Ca}_{\mathrm{v}} 1.2$ deficiency also results in heightened levels of phosphorylated (at S51) eIF $2 \alpha$ [150], a translational repressor. Both of these molecular findings support lower protein synthesis in $\mathrm{Ca}_{\mathrm{v}}$ 1.2-deficient mice. Altered protein synthesis, particularly heightened levels via the mTORC1 pathway has been implicated in both neurodevelopmental disorders, including ASD and neuropsychiatric disorders [176]. Preclinical mouse models with genetic manipulations of substrates of the mTORC1 pathway have been reported to display altered protein synthesis concurrent with neuropsychiatric-associated behavioral phenotypes, particularly social deficits [177-179]. Pharmacological manipulation of the mTOR pathway has been explored for treatment of neuropsychiatric disorders. For example, normalizing elevated protein synthesis with the mTOR inhibitor rapamycin [179] or inhibiting the mRNA translation factor, eIF4 [177, 178], has been shown to reverse social deficits. Supporting these preclinical findings a recent case study in a patient with the neurodevelopmental disorder, tuberous sclerosis complex (TSC), benefitted from the mTOR inhibitor everolimus. TSC in this patient resulted from a genetic deletion in TSC2, which increased mTOR activity, as seen in vitro experiments. Everolimus improved behavioral deficits (cognition, attention, social interaction, language development, and repetitive motor movements), seizures, and improved autism behavioral scores [180].

In contrast to the increase in general protein synthesis observed in several of the above mentioned models, $\mathrm{Ca}_{\mathrm{v}} 1.2$-deficient mice, as also seen in MeCP2-deficient mice [181], display lower general protein synthesis, suggesting that any disruption in translational regulation may induce overlapping behavioral endophenotypes. In support of this, inhibiting the effects of elevated phosphorylated eIF2 $\alpha$ S51 and lowering protein synthesis with ISRIB, a small molecule that potently inhibits the effects of eIF $2 \alpha$ [182], is sufficient to not only normalize the social deficits, but also to reverse the elevated anxiety-like behavior in forebrain $\mathrm{Ca}_{\mathrm{v}} 1.2$ conditional knockout mice [150]. Because of the lack of pharmacological agents that can elevate general protein synthesis via the mTORC1 pathway, ISRIB provides an alternative strategy to normalize the lower protein synthesis in mouse models such as forebrain $\mathrm{Ca}_{\mathrm{v}} 1.2$ conditional knockout mice. It is interesting that despite lower active mTOR, targeting eIF $2 \alpha$ is sufficient to normalize 
behavioral deficits, suggesting cross-talk between the mTOR and eIF $2 \alpha$ pathways [183].

These findings provide a unique role of $\mathrm{Ca}_{\mathrm{v}} 1.2$ in protein synthesis via the eIF $2 \alpha$ pathway and potentially the mTOR pathway (Fig. 2), and also identify a common $\mathrm{Ca}_{\mathrm{v}} 1.2$-mediated molecular mechanism underlying social and anxiety-like behaviors (Fig. 1). Furthermore, it identifies a novel target in a $\mathrm{Ca}_{\mathrm{v}}$ 1.2-deficient mouse model that can be manipulated in the adult brain to rescue behavioral deficits. The contribution of eIF $2 \alpha$ and its pathway to psychiatric and neurodevelopmental disease-associated symptoms remains unexplored but warrants further investigation. Increases in phosphorylation of eIF $2 \alpha$ at S51 can not only decrease translation of most mRNAs [184], but can also induce translation of a subset of mRNAs containing short upstream open reading frames in an activating transcription factor 4-dependent manner [146], a member of the CREB family of transcription factors [185]. Thus, further studies to explore the specific proteins targeted by elevated phosphorylated eIF $2 \alpha$ in the PFC of $\mathrm{Ca}_{\mathrm{v}} 1.2$-deficient mice that are modulating both anxiety and social function will be informative.

\section{Depressive-Like Behavior}

In addition to the above mentioned endophenotypes, depression-related symptoms are also commonly observed in BD, MDD, and SCZ [162]. In the late 1980s, a role for LTCCs in regulating depression-related behavior was first realized using LTCC pharmacological agents demonstrating that the DHP LTCC blocker nifedipine has an antidepressant-like effect in rats [186]. This was further expanded in a later study that showed that, in addition to nifedipine, other DHP blockers, including nicardipine, nitrendipine, isradipine, felodipine, and nimodipine but not amlodipine, had a similar antidepressant-like effect [187]. More recently, in support of the pharmacological antidepressant-like effect, the use of genetic mutant mice has revealed that $\mathrm{Ca}_{\mathrm{v}} 1.2$ heterozygous mice exhibit antidepressant-like behavior [152, 157]. Furthermore, focal knockdown of cacnalc $\left(\mathrm{Ca}_{\mathrm{v}} 1.2\right)$ in the adult PFC was sufficient to induce a similar antidepressant-like effect [152], consistent with antidepressants exerting their effects through cellular changes in the PFC [188].

In the context of CACNA1C SNPs the above findings suggest that gain of $\mathrm{Ca}_{\mathrm{v}} 1.2$ function mutations would contribute to depression-related symptoms. In support of this, it has been shown that pharmacological activation of LTCCs with the DHP activator BayK8644 induces a depressive-like phenotype [189]. Although depression-related behavior has not been tested in the $\mathrm{Ca}_{\mathrm{v}} 1.2$ gain-of-function TS mouse, there are case reports identifying 1 patient with TS with depression [48] and another patient with TS who developed BD in adulthood [41]. Together, these findings support the theory that gain of $\mathrm{Ca}_{\mathrm{v}} 1.2$ function results in depression-related symptoms.
It is intriguing that loss of $\mathrm{Ca}_{\mathrm{v}} 1.2$ in the $\mathrm{PFC}$ results in anxiety-like behavior but has an antidepressant-like effect. A deeper understanding of this differential effect of $\mathrm{Ca}_{\mathrm{v}} 1.2$ deficiency has come from molecular studies that have identified separate mechanisms influencing anxiety and depressionrelated behaviors. In contrast to dysregulation of the mRNA translation pathway underlying anxiety in $\mathrm{Ca}_{\mathrm{v}} 1$.2-deficient mice (described above), the regulated in development and DNA damage response 1 (REDD1; also known at DDIT4 or RTP801) pathway modulates depression-related behaviors (Fig. 1; [152]). $\mathrm{Ca}_{\mathrm{v}} 1.2$ heterozygous mice that exhibit an antidepressant-like phenotype have lower levels of the depression-related protein REDD1 in the PFC, and increasing levels of REDD1 in this anatomical region of adult $\mathrm{Ca}_{\mathrm{v}} 1.2$ heterozygous mice is sufficient to reverse the antidepressant-like phenotype [152]. This is consistent with present findings of higher REDD1 levels in the PFC of depressed patients [190].

Downstream of REDD1, the protein FoxO3a has been identified to play a role in modulating the antidepressant-like effect observed in $\mathrm{Ca}_{\mathrm{v}} 1.2$ heterozygous mice (Fig. 2; [152]). FoxO3a belongs to the FoxO family of transcription factors with SNPs within the FoxO3a gene linked to BD [191]. In rodents FoxO3a has been identified as a modulator of depression-related behavior [192]. FoxO3a knockout mice exhibit an antidepressant-like phenotype, and the antidepressant imipramine [193] and the mood stabilizer lithium [194] have been found to decrease levels of nuclear FoxO3a, suggesting that higher levels of nuclear FoxO3a may be associated with depressive behavior. In support of this, elevated levels of nuclear FoxO3a in the PFC of $\mathrm{Ca}_{\mathrm{v}} 1.2$ heterozygous mice, following REDD1 overexpression, has been associated with dampening the antidepressant-like phenotype seen in these mice [152]. These findings provide the first evidence of a role of the REDD1/FoxO3a signaling pathway in the PFC in regulating depression-related behavior in $\mathrm{Ca}_{\mathrm{v}} 1.2$ heterozygous mice (Figs. 1 and 2), and a new framework to study $\mathrm{Ca}_{\mathrm{v}} 1.2-$ associated depressive behavior.

\section{Cognitive Function}

Although not as broadly recognized as a symptom in neuropsychiatric disorders as changes in mood and emotion, cognitive impairments are a prominent feature of the CACNAICassociated psychiatric disorders, as well as ASD [195]. In particular, deficits within different aspects of learning and memory have been observed in BD, SCZ, MDD, ASD, and, to a lesser extent, ADHD [195]. Using rodent models, there is evidence that loss of $\mathrm{Ca}_{\mathrm{v}} 1.2$ influences discrete forms of learning and memory. In the hippocampal-dependent Morris water maze (MWM) spatial memory task, $\mathrm{Ca}_{\mathrm{v}} 1.2$ conditional knockout mice display normal acquisition and consolidation of the platform location with similar performance to the controls during the short- and long-term (24 hour) probe tests [150, 
196], whereas during the remote 30-day probe trial $\mathrm{Ca}_{\mathrm{v}} 1.2$ knockout mice display a significant deficit [196]. Recently, it has been demonstrated that by increasing the difficulty of the MWM task by decreasing the number of available spatial cues, $\mathrm{Ca}_{\mathrm{v}} 1.2$ conditional knockout mice exhibit a delay in the acquisition of the platform location and a significant deficit in the long-term memory probe test [197]. A similar hippocampaldependent deficit has been observed in the fear-associated context discrimination task [197]. This supports previous data by Moosmang et al. [198] demonstrating that $\mathrm{Ca}_{\mathrm{v}} 1.2$ channels in the hippocampus (using hippocampus-specific conditional knockout mice) are necessary for a hippocampal-dependent discriminatory water-maze task. This is supported by a role of $\mathrm{Ca}_{\mathrm{v}} 1.2$ in hippocampal long-term potentiation [198], a cellular model of learning and memory [199], as well as a role in adult hippocampal neurogenesis [149, 197], a cellular mechanism linked to learning/memory processes ([200, 201]; discussed below).

Similar to $\mathrm{Ca}_{\mathrm{v}} 1.2$-deficient mice, the $\mathrm{Ca}_{\mathrm{v}} 1.2$ gain-offunction TS mice display no deficit in learning and memory in the MWM spatial memory task or the Y-maze task [168]. However, when the hidden escape platform is moved to a different location to test reversal learning in both tasks, mice display a significant delay in determining the new platform location [168]. Because of this mild persistence in continuing to seek the original location of the platform in the MWM and repeatedly attempting to enter the arm of the Y-maze with the original platform, despite the presence of a physical obstruction, the authors interpret these observations as evidence of repetitive, restrictive, and perseverative behavior [168], and possibly a sign of lack of cognitive flexibility, seen in disorders such as SCZ [202]. In contrast to these findings, loss of $\mathrm{Ca}_{\mathrm{v}} 1.2$ in the glutamatergic neurons of the forebrain appears to negatively impact learning and memory in the Y-maze hidden-platform task [150], an observation that begs further exploration on the anatomical and cell-type specificity of loss of $\mathrm{Ca}_{\mathrm{v}} 1.2$ signaling.

Separately from studies in rodents, it is clear that the LTCCs also play an important role in fear-associated memories, the most common behavioral paradigm utilized to study the biological basis of emotion [203-205]. This is not surprising given that altered emotional processing has been reported in patients with SCZ, BD, and ADHD [206]. In rodents, it has been observed that systemic inhibition of LTCCs with nifedipine had no impact on the acquisition or long-term expression of cue-associated fear memories [207]. However, focal delivery of verapamil in the basolateral amygdala, a brain region involved in fear, of adult rats immediately prior to fear conditioning blocked cue-associated long-term fear memory but not the short-term memory [208]. Similarly, focal delivery of the LTCC blockers verapamil or nifedipine into the basolateral amygdala of adult rats immediately before cue extinction training impaired the long-term memory of fear extinction [209]. This is consistent with a previous study that showed impaired cue extinction with systemic administration of the LTCC blockers nifedipine and nimodipine [207]. These studies suggest that differential LTCC-mediated mechanisms are being recruited for acquisition versus extinction of cueassociated fear memories.

Using genetic mutant mice, recent studies have focused on dissociating the differential contribution of the $\mathrm{Ca}_{\mathrm{v}} 1.2$ and $\mathrm{Ca}_{\mathrm{v}} 1.3$ isoforms in fear processes. In agreement with pharmacological studies, brain-specific $\mathrm{Ca}_{\mathrm{v}} 1.2$ knockout mice have no deficit in the consolidation and recall of a cue-associated fear memory [210]. However, selective conditional knockout of $\mathrm{Ca}_{\mathrm{v}} 1.2$ in glutamatergic neurons of the forebrain display enhanced freezing during the long-term cue-associated fear memory test [150]. This discrepancy is most likely a result of compensatory upregulation of $\mathrm{Ca}^{2+}$-permeable glutamate $\alpha$-amino-3-hydroxy-5-methyl-4-isoxazolepropionic acid receptors (AMPARs) in the amygdala [210]. Interestingly in the $\mathrm{Ca}_{\mathrm{v}} 1.2$ gain-of-function TS mouse, an increase in freezing during the long-term cue-associated fear memory test has been reported [168], suggesting that too much or too little $\mathrm{Ca}_{\mathrm{v}} 1.2$ signaling can have similar behavioral phenotypes in certain tasks. Interestingly, in contextual fear conditioning, loss of $\mathrm{Ca}_{\mathrm{v}} 1.2$ in genetic mutant mice $[197,211]$ did not impact freezing during the context-associated fear memory test. In contrast, the $\mathrm{Ca}_{\mathrm{v}} 1.2$ gain-of-function TS mice exhibited enhanced freezing during the context-associated fear memory test [168], identifying that loss and gain of function can have differential effects of certain brain region-specific tasks. In addition to the conventional fear-conditioning paradigms, LTCC inhibitors have been shown to block latent inhibition of conditioned fear [212] and fear-potentiated startle [213], suggesting a role of these channels in other forms of emotional learning and plasticity.

The mechanism underlying altered fear memories described above are not known. Late-phase long-term potentiation (LTP) at thalamic inputs to the lateral amygdala, a mechanism that requires LTCCs [198, 208, 214, 215], has been associated with cue fear conditioning [216]. One molecule that mediates LTP in the thalamoamygdala pathway is brainderived neurotrophic factor (BDNF) [217], a downstream target of LTCCs [149, 218]. Induction of BDNF in the amygdala is required for consolidation of fear memories [219]. Supporting these findings, administration of the LTCC inhibitor verapamil blocks the induction of BDNF after cueassociated fear conditioning [220]. The findings from this study suggest that this occurs as a result of lack of activation of CaMKIV [220], a CREB kinase and a downstream target of LTCCs [221], resulting in decreased binding of phosphorylated CREB at the promoter regions of BDNF [220]. This is consistent with previous studies that have identified LTCCs as critical regulators of BDNF expression both in vitro [222] and in vivo [149]. Currently, the specific LTCC isoform 
mediating this fear conditioning-induced LTP in the thalamoamygdalar pathway is unknown.

\section{Ca $_{v}$ 1.2 Channels, Adult Hippocampal Neurogenesis, and Neuropsychiatric-Related Phenotypes}

Adult hippocampal neurogenesis that involves addition of newborn neurons (granule cells) to the dentate gyrus of the hippocampus throughout life has been implicated in the pathology underlying SCZ, based on rodent models of the disorder [223-230], BD based on genes associated with the disorder [137, 231], and depression [232, 233], autism [234-237], and ADHD, based on rodent disease models $[229,235,238]$. Rodent behavioral studies suggest a role of adult hippocampal neurogenesis in many of the phenotypes related to these disorders that are also observed in $\mathrm{Ca}_{\mathrm{v}} 1.2-$ deficient mice described above, including memory formation [200, 201], context discrimination [239], modulation of anxiety and depressive-like behavior [240], as well as mediating the effects of antidepressants. In support of this, 2 independent studies have identified a deficit in adult hippocampal neurogenesis in mice with loss of $\mathrm{Ca}_{\mathrm{v}} 1.2$ restricted to glutamatergic neurons of the forebrain [149] and in neurons of the entire brain [197]. This is consistent with a previous in vitro study identifying a role of LTCCs in activity-dependent regulation of adult-derived neural precursor cells [241].

The deficit in adult hippocampal neurogenesis in $\mathrm{Ca}_{\mathrm{v}} 1.2$ conditional knockout mice is specific to survival and not proliferation of neural precursor cells (NPCs) [149]. This finding is supported by an in vitro study that has identified a role of LTCCs during the later neurogenic stages of survival and maturation of NPCs derived from adult rat hippocampus [242]. As adult hippocampal neurogenesis is a highly regulated process and results from a balance of proliferation of NPCs and the survival of young newborn neurons into which NPCs differentiate [243], the discovery of $\mathrm{Ca}_{\mathrm{v}} 1.2$ channels in supporting the survival of newborn neurons suggests that this stage of adult neurogenesis may be important for certain aspects of neuropsychiatric disease.

The precise mechanism of the deficit in survival of newborn neurons remains unknown. Given that $\mathrm{Ca}_{\mathrm{v}} 1.2$ expression is restricted to mature young hippocampal neurons in adult mice [244], one potential mechanism is via the neurotrophic factor, BDNF. LTCCs mediate BDNF production in glutamatergic neurons of the hippocampus [149], release of which acts on both the secreting neuron and neighboring neurons [245]. LTCCs serve as a primary $\mathrm{Ca}^{2+}$ source for $B d n f$ transcriptional regulation, particularly at the promoter of $B d n f$ exon IV, a splice variant critically involved in experiencedependent neuronal plasticity [246-249]. Multiple LTCCactivated transcription regulators, including CREB, $\mathrm{Ca}^{2+}$ response factor, and $\mathrm{MeCP} 2$, which are also involved in regulating adult hippocampal neurogenesis $[127,237,250$, 251], control $B d n f$ expression by binding to $B d n f$ exon IV promoter in hippocampal neurons [222, 252-255]. Thus, it is plausible that lack of activation of these factors in the hippocampus results in lower BDNF and thus lowers survival of newborn neurons. This mechanism may also contribute to the LTP deficit observed in hippocampal-specific $\mathrm{Ca}_{\mathrm{v}} 1.2$ knockout mice [198] as BDNF signaling and adult newborn neurons are required for hippocampal-dependent learning and memory processes [256]. Additionally, BDNF is a key player in regulating mood-related phenotypes [257]. Thus, collectively, it is plausible that the lower survival of adult born neurons as a result of $\mathrm{Ca}_{\mathrm{v}} 1.2 / \mathrm{BDNF}$ deficiency could contribute to the neuropsychiatric-related phenotypes observed in $\mathrm{Ca}_{\mathrm{v}} 1.2$-deficient mice, a mechanism to be confirmed in future studies.

Another key question is whether restoring reduced survival of newborn neurons is sufficient to rescue phenotypes observed in $\mathrm{Ca}_{\mathrm{v}} 1.2$-deficient mice. Using the neuroprotective aminopropyl carbazole P7C3-A20, a small molecule that blocks neuronal cell death [258-264] and thus increases cell survival of hippocampal newborn neurons [243, 265, 266], it has been found that this compound is capable of restoring hippocampal neurogenesis to normal levels in forebrain $\mathrm{Ca}_{\mathrm{v}} 1.2$ conditional knockout mice [149]. This therapeutic effect occurred despite a lack in the normalization of BDNF levels. Given that BDNF-enhancing agents have not proved to be effective therapeutically to date, P7C3-A20 offers an alternative therapeutic mechanistic route to restore impaired adult neurogenesis in $\mathrm{Ca}_{\mathrm{v}}$ 1.2-deficient mice that circumvents lower BDNF signaling. If P7C3-A20 is able to rescue behavioral deficits, this work may provide new treatment opportunities for patients suffering from $C A C N A 1 C$-associated neuropsychiatric symptoms. Additionally the identification of a previously unidentified role for $\mathrm{Ca}_{\mathrm{v}} 1.2$ channels in neuronal cell survival may provide novel insight and approaches to treating neuropsychiatric disease, particularly in situations of decreased $\mathrm{Ca}_{\mathrm{v}} 1.2$ or loss of $\mathrm{Ca}_{\mathrm{v}} 1.2$ function.

\section{$\mathrm{Ca}_{\mathbf{v}}$ 1.2, Excitatory/Inhibitory Imbalance and Neuropsychiatric Phenotypes}

One emerging hypothesis for the pathophysiological mechanisms underlying the behavioral impairments in neuropsychiatric disorders is altered synaptic excitation (E) to inhibition (I) balance [151, 267], a cellular perturbation reported in multiple mouse models exhibiting anxiety-like behavior, altered social behavior, and impaired cognitive function [150, 177, 178, 267-269]. However, the impact of loss or gain of LTCC function on synaptic E/I balance and its impact on behavior remains largely unknown. In vitro pharmacological studies have provided evidence that LTCC-mediated mechanisms modulate synaptic plasticity in a homeostatic fashion 
[270]. Cortical neurons treated for 24 hours with the LTCC blocker nifedipine have been shown to increase both frequency and amplitude of miniature excitatory postsynaptic currents [271]. Furthermore, in hippocampal neurons, 24-hour blockade of LTCCs with nifedipine has been found to decrease the expression of synaptic $\gamma$-aminobutryic acid A receptors [272], which mediate inhibitory neurotransmission, suggesting that LTCCs can modulate E/I balance. This is supported by an in vivo study, which found that loss of $\mathrm{Ca}_{\mathrm{v}} 1.2$ in glutamatergic neurons of the forebrain results in higher frequency and amplitude of miniature excitatory postsynaptic currents in layer-5 neurons of the PFC, suggesting an increase in the overall E/I balance in this region [150], supporting other mouse models of neuropsychiatric disorders with higher E/I associated with neuropsychiatric-related behaviors.

These in vivo and in vitro studies suggest that chronic loss of LTCC signaling can have long-term consequences on synaptic scaling and, subsequently, function. The precise mechanism underlying this synaptic plasticity is not known. There are, however, 2 possible mechanisms that may be involved. First, impaired LTCC signaling may impact on nuclear transcriptional processes that can subsequently affect dendritic synaptic protein changes. This possibility is supported by an in vitro study that found that 24-hour inhibition of LTCCs results in increased (as opposed to the expected decrease) CREB-dependent transcription of the GluA1 subunit of the excitatory AMPARs [271]. Second, loss of LTCC signaling can negatively affect the mRNA translation machinery within spines and alter the composition of synaptic proteins [150]. These findings add to the growing literature that neuropsychiatric disorders are disorders of the synapse and that altered $\mathrm{Ca}_{\mathrm{v}} 1.2$ signaling, even though shown not to impact spine and dendritic architecture $[198,210]$ as opposed to $\mathrm{Ca}_{\mathrm{v}} 1.3$ channels $[28,273]$, can impact synaptic function via secondary homeostatic effects.

\section{$\mathrm{Ca}_{\mathrm{v}}$ 1.3 Channels and Neuropsychiatric-Related Phenotypes}

\section{Anxiety-Like, Depressive-Like, and Social Behavior}

Using rodent preclinical models, $\mathrm{Ca}_{\mathrm{v}} 1.3$ channels, although less studied than $\mathrm{Ca}_{\mathrm{v}} 1.2$ channels, also modulate neuropsychiatric-related endophenotypes. $\mathrm{Ca}_{\mathrm{v}} 1.3$-deficient mice demonstrate an anxiolytic-like phenotype [274], although this effect may be attributed to the congenital deafness observed in these mice [275]. This is supported by recent findings in $\mathrm{Ca}_{\mathrm{v}} 1.2 \mathrm{DHP}^{-/-}$mice wherein treatment with the LTCC activator BayK8644, which selectively activates $\mathrm{Ca}_{\mathrm{v}} 1.3$ channels, does not induce anxiety-like behavior [51]. In contrast to this, $\mathrm{Ca}_{\mathrm{v}} 1.3$ regulates depressive-like behavior with $\mathrm{Ca}_{\mathrm{v}} 1.3$ deficiency resulting in an antidepressant-like phenotype [274], whereas systemic activation of the $\mathrm{Ca}_{\mathrm{v}} 1.3$ channels induces a depressive-like phenotype [159]. $\mathrm{Ca}_{\mathrm{v}} 1.3$ channel activation with BayK8644 has also been found to induce a deficit in social behavior [51], in support of $\mathrm{Ca}_{\mathrm{v}} 1.3$ gain-of-function mutations associated with ASD [7, 54]. The systemic effect of $\mathrm{Ca}_{\mathrm{v}} 1.3$ channel activation on depressionrelated and social behaviors has been attributed to its role in the ventral tegmental area (VTA) [51], supporting the role of dopaminergic neurotransmission in both depressive and social behavior (discussed below).

\section{Cognitive Function}

Rodent studies have identified a role of $\mathrm{Ca}_{\mathrm{v}} 1.3$ in certain forms of learning and memory. Although $\mathrm{Ca}_{\mathrm{v}} 1.3$-deficient mice displayed no deficit in the MWM spatial memory task [276], these mice have significantly impaired object location memory in a discrimination test [244], suggesting that $\mathrm{Ca}_{\mathrm{v}} 1.3$ channels may be recruited in specific spatial memory tasks. However, given the findings of Temme et al. [197] that $\mathrm{Ca}_{\mathrm{v}} 1.2$ is recruited when the difficulty of the MWM is increased, it would be interesting to test $\mathrm{Ca}_{\mathrm{v}} 1.3$-deficient mice in a similar task, particularly given the deficit in adult hippocampal neurogenesis observed in these mice ([244]; reviewed below). In the contextual fear-conditioning test, $\mathrm{Ca}_{\mathrm{v}} 1.3$ channels are not required during acquisition or extinction of the conditioned memory [106, 276], but play an important role in the consolidation of the context-associated fear memory [276]. This has been attributed to reduced LTP in the basolateral amygdala [277].

\section{Adult Hippocampal Neurogenesis}

In contrast to the high expression of $\mathrm{Ca}_{\mathrm{v}} 1.2$ LTCCs in the hippocampus, $\mathrm{Ca}_{\mathrm{v}} 1.3$ channels are expressed at much lower levels [278]. Despite this, loss of $\mathrm{Ca}_{\mathrm{v}} 1.3$ channels has a profound effect on adult hippocampal neurogenesis [244]. $\mathrm{Ca}_{\mathrm{v}} 1.3$ knockout mice display a deficit in both proliferation of neural progenitor cells and survival of newborn hippocampal neurons [244], an effect not observed following deletion of $\mathrm{Ca}_{\mathrm{v}} 1.2$ channels that only impacts survival [149]. These differential roles of $\mathrm{Ca}_{\mathrm{v}} 1.2$ and $\mathrm{Ca}_{\mathrm{v}} 1.3$ may be a consequence of the differential expression of $\mathrm{Ca}_{\mathrm{v}} 1.2$ and $\mathrm{Ca}_{\mathrm{v}} 1.3$ channels in the adult neurogenic regions [244]. While $\mathrm{Ca}_{\mathrm{v}} 1.2$ is expressed exclusively in mature young hippocampal neurons, $\mathrm{Ca}_{\mathrm{v}} 1.3$ is expressed in both newly formed immature NPCs, as well as mature young hippocampal neurons [244]. The contribution of reduced adult hippocampal neurogenesis to mood and learning/memory behaviors as a result of deficient $\mathrm{Ca}_{\mathrm{v}} 1.3$ remains currently unknown, but it is plausible that it could contribute to the mood and memory deficits associated with dysregulated $\mathrm{Ca}_{\mathrm{v}} 1.3 \mathrm{Ca}^{2+}$ signaling. 


\section{L-Type $\mathrm{Ca}^{2+}$ Channels and Drug Dependence}

LTCCs have been demonstrated to play a role in mediating the effects of multiple drugs of abuse, including psychostimulants (cocaine, amphetamine), opioids (morphine), alcohol, and nicotine. To date, no genetic studies have been reported linking CACNA1C to drug dependence; however, CACNA1C-risk SNP carriers have altered reward processing [279], and a recent study has weakly linked CACNAIC to food addiction [280]. In contrast, recent work has identified a significant association between CACNAID and cocaine dependence [51]. Below we review both LTCC pharmacological studies (summarized in Table 3) and LTCC isoform-specific contribution to drug dependence-specific phenotypes in rodent models.

\section{Cocaine}

In rodents, pharmacological studies have established an important role of LTCCs in various aspects of cocaine's effects. LTCC blockers, nimodipine, nifedipine, and diltiazem have been shown to attenuate the development and expression of cocaine behavioral sensitization [160, 283, 284], a model of drug-induced plasticity [320-322]. Using cocaineconditioned place preference (CPP), a model used to study the rewarding effects of drugs [281], isradipine [282, 285] and nifedipine [51, 286, 287] diminish the rewarding effects of cocaine. Additionally, using cocaine self-administration, a model of the reinforcing effects of drugs [323], isradipine and nimodipine attenuate the reinforcing effects of cocaine [288].

LTCC blockers have also demonstrated efficacy in rodent models of relapse to cocaine-seeking behavior, one of the central clinical problems in treating cocaine addiction. In a selfadministration model of relapse following extinction of cocaine-seeking behavior, diltiazem treatment in the nucleus accumbens (NAc) has been shown to block the effects of cocaineprimed seeking behavior [289]. Similarly, blocking LTCCs with isradipine in the VTA has also shown efficacy in attenuating cocaine-seeking behavior following exposure to drugassociated cues in drug-abstinent rats [324], another model of relapse. Of clinical significance, this study found that isradipine had no effect on sucrose-seeking behavior, suggesting that isradipine could be directly targeted in cocaine-dependent individuals without affecting their natural reward processing.

Studies addressing the specific role of the individual LTCC isoforms have identified a critical role of the $\mathrm{Ca}_{\mathrm{v}} 1.3$ LTCCs in dopaminergic neurons of the VTA in the development of cocaine behavioral sensitization [325] and the acquisition of cocaine CPP [51]. Given that $\mathrm{Ca}_{\mathrm{v}} 1.3$ channels are the primary Ltype subunit in VTA dopamine neurons [15], the effects of isradipine in the VTA on attenuation of cocaine CPP [282] and cocaine-seeking behavior [324] are most likely due to its effects on $\mathrm{Ca}_{\mathrm{v}} 1.3$ channels. However, VTA $\mathrm{Ca}_{\mathrm{v}} 1.2$ channels may also play a role as they mediate acute responses [326] and VTA physiology [327]. In contrast, $\mathrm{Ca}_{\mathrm{v}} 1.2$ channels play a role in mediating the long-term effects of cocaine via its effects in the NAc [160, 161].

Molecular studies find that $\mathrm{Ca}_{\mathrm{v}} 1.3$ channels activate the CamKII/ERK pathway in the VTA and $\mathrm{Ca}_{\mathrm{v}} 1.2$ channels in the NAc activate CamKII (Fig. 2), which increases GluA1 phosphorylation and elevates surface expression of GluA1 [161]. Recently, these findings have been extended to demonstrate that $\mathrm{Ca}^{2+}$-permeable AMPARs (CP-AMPARs) in the NAc mediate the long-term effects of cocaine (Fig. 1) [51], and add to the growing body of evidence that long-lasting addiction-related behaviors are mediated by an increase in NAc CP-AMPAR neurotransmission [328].

\section{Morphine}

LTCCs have also been shown to play a role in the rewarding effects of morphine. The LTCC blockers nimodipine, nifedipine, and verapamil attenuate the development of morphine sensitization [290]. Similarly, isradipine and nifedipine attenuate the rewarding effects of morphine using CPP [286, 287, 291], and isradipine and nimodipine suppress the reinforcing effects of morphine using self-administration [288].

A major aspect of morphine and opioids, in general, is the manifestation of physical withdrawal symptoms [329]. This can be modeled in rodents by precipitating withdrawal symptoms with the use of the compound naloxone [330, 331]. Multiple studies have also shown that LTCC blockers when administered prior to (nifedipine, nimodipine, verapamil [292]), along with (diltiazem, nimodipine, nifedipine [293, 294, 298-300]) or after morphine treatment (verapamil, nimodipine, diltiazem, nicardipine [295-297]) can alleviate physical withdrawal symptoms, suggesting that LTCC blockers may be helpful in easing withdrawal symptoms following onset.

The molecular mechanisms by which LTCCs mediate the effects of morphine remain unknown. However, there is evidence of increased $\mathrm{Ca}_{\mathrm{v}} 1.2$ and $\mathrm{Ca}_{\mathrm{v}} 1.3$ protein levels in the frontal cortex and limbic forebrain regions of mice exposed to morphine [287, 332]. Separately, it has also been reported that chronic morphine treatment results in a decrease in $\mathrm{Ca}_{\mathrm{v}} 1.3$ but not $\mathrm{Ca}_{\mathrm{v}} 1.2$ protein levels in midbrain regions (pons, midbrain, and medulla [333]). Together, these findings suggest that morphine may regulate $\mathrm{Ca}_{\mathrm{v}} 1.2$ and $\mathrm{Ca}_{\mathrm{v}} 1.3$ in a brain region-specific manner.

\section{Ethanol}

Pharmacological studies provide evidence that LTCCs are important mediators of the effects of ethanol. Verapamil, isradipine, nifedipine, felodipine, nimodipine, nicardipine, nitrendipine, diltiazem, and verapamil reduce ethanol 
Table 3 L-Type calcium-channel pharmacological studies and its contribution to drug dependence-specific phenotypes in rodent models

\begin{tabular}{|c|c|c|c|c|}
\hline Drug & Behavioral paradigm & LTCC blocker & Behavioral outcome & Reference \\
\hline \multirow[t]{8}{*}{ Cocaine } & \multirow[t]{3}{*}{ Behavioral sensitization } & Nimodipine & \multirow{3}{*}{$\begin{array}{l}\text { Suppressed development }[157,281] \\
\text { and expression }[157,282] \text { of } \\
\text { sensitization }\end{array}$} & [283] \\
\hline & & Nifedipine & & {$[160]$} \\
\hline & & Diltiazem & & [284] \\
\hline & \multirow[t]{3}{*}{ Conditioned place preference } & Isradipine & \multirow[t]{3}{*}{ Decreased conditioned place preference } & {$[282,285]$} \\
\hline & & Nifedipine and verapamil & & [286] \\
\hline & & Nifedipine & & {$[51,287]$} \\
\hline & Self-administration & Isradipine and nimodipine & Decreased self administration & [288] \\
\hline & $\begin{array}{l}\text { Self-administration: } \\
\text { cocaine-primed reinstatement }\end{array}$ & Diltiazem & $\begin{array}{l}\text { Decreased reinstatement of cocaine } \\
\text { seeking following extinction }\end{array}$ & [289] \\
\hline \multirow[t]{12}{*}{ Morphine } & Behavioral sensitization & Nimodipine, nifedipine, and verapamil & Suppressed development of sensitization & [290] \\
\hline & \multirow[t]{3}{*}{ Conditioned place preference } & Nifedipine, verapamil & \multirow[t]{3}{*}{ Decreased conditioned place preference } & [286] \\
\hline & & Nifedipine & & [287] \\
\hline & & Isradipine & & [291] \\
\hline & Self-administration & Isradipine and nimodipine & Decreased self-administration & [288] \\
\hline & \multirow[t]{5}{*}{$\begin{array}{l}\text { Naloxone-induced } \\
\text { withdrawal }\end{array}$} & $\begin{array}{l}\text { Nifedipine, nimodipine and verapamil } \\
\text { (prior to morphine) }\end{array}$ & Attenuated the withdrawal effects & [292] \\
\hline & & Diltiazem (along with morphine) & \multirow[t]{4}{*}{ Attenuated the withdrawal effects } & {$[293,294]$} \\
\hline & & $\begin{array}{l}\text { Verapamil (after morphine but before } \\
\text { naloxone) }\end{array}$ & & [295] \\
\hline & & $\begin{array}{l}\text { Verapamil, nimodipine (after morphine } \\
\text { but before naloxone) }\end{array}$ & & [296] \\
\hline & & $\begin{array}{l}\text { Verapamil, nicardipine and diltiazem } \\
\text { (after morphine but before naloxone) }\end{array}$ & & [297] \\
\hline & \multirow{2}{*}{$\begin{array}{l}\text { Withdrawal after chronic } \\
\text { morphine }\end{array}$} & Nimodipine (along with morphine) & \multirow{2}{*}{$\begin{array}{l}\text { Attenuated some of the withdrawal } \\
\text { effects }\end{array}$} & {$[298,299]$} \\
\hline & & Nifedipine (along with morphine) & & [300] \\
\hline \multirow[t]{15}{*}{ Ethanol } & \multirow[t]{6}{*}{ Consumption } & Nifedipine & \multirow[t]{4}{*}{ Decreased ethanol intake } & [301] \\
\hline & & Verapamil & & [302] \\
\hline & & Nifedipine, verapamil and isradipine & & [303] \\
\hline & & $\begin{array}{l}\text { Nifedipine, felodipine, nimodipine, } \\
\text { isradipine, nicardipine, nitredipine } \\
\text { and } \\
\text { diltiazem }\end{array}$ & & [304] \\
\hline & & Isradipine and nifedipine & \multirow[t]{2}{*}{ No effect } & [305] \\
\hline & & Nimodipine & & [306] \\
\hline & \multirow[t]{2}{*}{ Locomotor activity } & $\begin{array}{l}\text { Nifedipine } \\
\text { Verapamil and diltiazem }\end{array}$ & $\begin{array}{l}\text { Decreased locomotor activity induced } \\
\text { by low dose of ethanol }(2.5 \mathrm{~g} / \mathrm{kg}) \\
\text { exposure }\end{array}$ & {$[301,307,308]$} \\
\hline & & Nifedipine and verapamil & $\begin{array}{l}\text { No effect after chronic treatment of the } \\
\text { blockers }\end{array}$ & [309] \\
\hline & Self-administration & Verapamil & $\begin{array}{l}\text { Prevented cue-primed reinstatement } \\
\text { following } 21 \text { days of abstinence }\end{array}$ & {$[20]$} \\
\hline & $\begin{array}{l}\text { Withdrawal following chronic } \\
\text { ethanol consumption }\end{array}$ & Nitrendipine & Reduced withdrawal symptoms & {$[310,311]$} \\
\hline & \multirow{2}{*}{$\begin{array}{l}\text { Withdrawal following chronic } \\
\text { ethanol inhalation }\end{array}$} & Nitrendipine & Reduced withdrawal symptoms & {$[310,311]$} \\
\hline & & $\begin{array}{l}\text { Nimodipine, nitrendipine and } \\
\text { isradipine }\end{array}$ & $\begin{array}{l}\text { Reduced convulsive behavior } \\
\text { during withdrawal }\end{array}$ & [310] \\
\hline & $\begin{array}{l}\text { Withdrawal following binge } \\
\text { drinking }\end{array}$ & Nimodipine & $\begin{array}{l}\text { Reduced withdrawal symptoms } \\
\text { following binge drinking }\end{array}$ & [312] \\
\hline & \multirow{2}{*}{$\begin{array}{l}\text { Chronic alcohol-induced } \\
\text { seizures }\end{array}$} & Nifedipine & \multirow{2}{*}{$\begin{array}{l}\text { Reduced chronic alcohol-induced } \\
\text { seizures }\end{array}$} & [313] \\
\hline & & Nifedipine and nimodipine & & [314] \\
\hline \multirow[t]{2}{*}{ Nicotine } & Locomotor activity & Nimodipine & $\begin{array}{l}\text { Reduced acute nicotine induced } \\
\text { locomotor activity }\end{array}$ & [315] \\
\hline & $\begin{array}{l}\text { Behavioral sensitization; } \\
\text { Locomotor activity }\end{array}$ & $\begin{array}{l}\text { Nimodipine, verapamil and } \\
\text { diltiazem }\end{array}$ & $\begin{array}{l}\text { Suppressed development and expression } \\
\text { of behavioral sensitization }\end{array}$ & [316] \\
\hline
\end{tabular}

Nifedipine 
Table 3 (continued)

\begin{tabular}{lllll}
\hline Drug & Behavioral paradigm & LTCC blocker & Behavioral outcome & Reference \\
\hline & & $\begin{array}{c}\text { Suppressed expression of behavioral } \\
\text { sensitization } \\
\text { Reduced withdrawal symptoms }\end{array}$ \\
Mecamylamine-induced withdrawal & $\begin{array}{c}\text { Nimodipine, verapamil and } \\
\text { diltiazem }\end{array}$ & Attenuated withdrawal- induced anxiety & {$[315,318]$} \\
Withdrawal from acute nicotine & $\begin{array}{c}\text { Nimodipine, verapamil and } \\
\text { diltiazem }\end{array}$ & Nimodipine and verapamil \\
$\begin{array}{c}\text { Withdrawal from chronic } \\
\text { nicotine treatment }\end{array}$ & No effect on withdrawal-induced anxiety & {$[319]$} \\
\hline
\end{tabular}

consumption [301-304], and nifedipine, verapamil, and diltiazem decrease the heightened locomotor activity induced by low doses of ethanol [301, 307, 308]. In contrast, a study reported that nifedipine and verapamil had no impact on the ethanol-induced increase in locomotor activity [309], nor did isradipine, nifedipine or nimodipine on ethanol consumption $[305,306]$. This discrepancy in findings may rely mainly on the different doses of LTCC blockers used. Verapamil has also been shown to block alcohol-seeking behavior in response to alcohol-associated cues following abstinence using selfadministration [20], and mice deficient in $\mathrm{Ca}_{\mathrm{v}} 1.2$ in forebrain glutamatergic neurons show a deficit in alcohol-seeking behavior [20]. These behavioral findings are consistent with the previous report showing that protracted abstinence from alcohol increases $\mathrm{Ca}_{\mathrm{v}} 1.2$ but not $\mathrm{Ca}_{\mathrm{v}} 1.3$ in the amygdala and hippocampus [20], 2 brain regions involved in mediating the effects of alcohol [334-336].

Separately, nitrendipine has been shown to reduce withdrawal symptoms when administered during chronic ethanol exposure [310, 311]. Excessive ethanol consumption in a short period of time (also referred to as "binge drinking") can be mimicked in rodents, with nimodipine reducing the withdrawal effects resulting from binge drinking [312]. Furthermore, nifedipine and nimodipine have been found to reduce seizures that occur during withdrawal from chronic alcohol [313,314], a symptom suggested to be driven, in part, by increased LTCC currents [337]. Similarly, nimodipine, nitrendipine, and isradipine can also decrease the convulsive behavior associated with chronic ethanol withdrawal [338].

\section{Nicotine}

As with other drugs of abuse, the continuous use of nicotine results in dependency and adverse withdrawal symptoms while in abstinence [339]. Acute nicotine treatment in mice increases forebrain $\mathrm{Ca}_{\mathrm{v}} 1.3$ mRNA levels 24 hours after exposure, while chronic nicotine treatment alters $\mathrm{Ca}_{\mathrm{v}} 1.2$ mRNA levels [16]. Additionally, cortical neurons exposed to long-term nicotine, enhances $\mathrm{Ca}_{\mathrm{v}} 1.2$ and $\mathrm{Ca}_{\mathrm{v}} 1.3$ protein levels [340]. This was later confirmed by chronic nicotine treatment for 7 days in mice that led to an increase in $\mathrm{Ca}_{\mathrm{v}} 1.2$ and $\mathrm{Ca}_{\mathrm{v}} 1.3$ protein levels in the cortex [341]. Behaviorally, LTCC blockers have been shown to attenuate acute nicotine-induced locomotor activity (nimodipine [315]), as well as decrease the development (nimodipine, verapamil, diltiazem [316]) and expression (nimodipine, verapamil, diltiazem, nifedipine [16, 316]) of nicotine behavioral sensitization. Similarly, treatment with nimodipine, diltiazem, and verapamil reduced the rewarding effects of nicotine using CPP [316]. Moreover, nimodipine was capable of attenuating nicotine-induced drug seeking using the self-administration paradigm [318].

Nicotine dependent individuals undergo physical withdrawal that can be modeled in rodents using the compound mecamylamine [342]. Nimodipine, verapamil, and diltiazem have been shown to attenuate the mecamylamine-induced withdrawal symptoms [317]. Anxiety is one of the most common features observed in nicotine-dependent individuals when they abstain from smoking [343]. Nimodipine, verapamil, and diltiazem reduced the anxiogenic effects during withdrawal resulting from acute nicotine treatment [318]. However, one study found that nimodipine and verapamil administered during withdrawal from nicotine had no impact on the anxiogenic effect of chronic nicotine treatment [319]. These studies suggest that LTCCs can modulate nicotineinduced anxiety only if the blocker is administered before nicotine dependency.

\section{Model of Comorbid Mood and Substance Use Disorders}

Genetic factors significantly influence susceptibility to mood disorders and substance abuse that are often comorbid, particularly as seen for BD and cocaine dependence [344], conditions linked to $C A C N A 1 D[31,49,51]$. Overlapping neural circuitry and convergent cellular and molecular mechanisms have been suggested to underlie such comorbidity [345-347]. As reviewed above, emerging data on the impact of CACNA1D mutations on $\mathrm{Ca}_{\mathrm{v}} 1.3$ physiology [7, 54], together with animal studies, suggest that enhanced $\mathrm{Ca}_{\mathrm{v}} 1.3$ activity (resulting from gain-of-function mutations or increased gene expression from noncoding variants) may contribute to co- 
occurring mood and drug-dependence phenotypes. Recent rodent studies have found that common molecular mechanisms can regulate depressive-like behavior, deficits in social behavior, and cocaine-related behaviors [348-352]. In support of the human genetic findings, work from our laboratory has identified that repeated activation of $\mathrm{Ca}_{\mathrm{v}} 1.3$ channels in the VTA in $\mathrm{Ca}_{\mathrm{v}} 1.2 \mathrm{DHP}^{-/-}$mice, with high $\mathrm{Ca}_{\mathrm{v}} 1.3$ expression [15], is sufficient to induce depressive-like behavior, social deficits, and cocaine-related behaviors [51]. A potential mechanism could be via $\mathrm{Ca}_{\mathrm{v}} 1.3$ channels increasing burst firing of VTA dopamine neurons [327], a neuronal property known to mediate depressive-like behavior [353-355], social behavior [356], and reward-related behavior [357].

The NAc is another key brain reward region that mediates the effects of all 3 behaviors, and molecular adaptations within this region drive long-term behavioral changes [347, 358, 359], a crucial problem in substance abuse disorders and possibly depressive behavior and social impairments, particularly following stressful insults. In fact, it has been shown that the
NAc mediates the effects of $\mathrm{Ca}_{\mathrm{v}} 1.3$ channel activation in the VTA [51]. This is not surprising as the VTA-NAc mesolimbic pathway has a central role in mediating the effects of depressive-like behavior [353, 354], social behavior [356], and cocaine [360], with glutamatergic signaling in the NAc driving many of these behaviors [328]. In support of this, depressive-like and cocaine behaviors resulting from VTA $\mathrm{Ca}_{\mathrm{v}} 1.3$ activation are mediated by increased CP-AMPARs in the NAc shell, whereas social deficits are mediated by increased GluA1/GluA2 AMPARs in the NAc core [51], 2 subregions demonstrated to play distinct roles within the brain's reward pathway [361]. This is consistent with studies that have identified CP-AMPARs as a key synaptic mechanism underlying cocaine-behaviors [328] and heightened AMPAR activity in the NAc as a mediator of depressive [362-364] and social behaviors [365]. Together, these findings provide evidence of a useful, disease relevant model to study mechanisms of co-occurring mood- and cocaine-dependence-related behavioral phenotypes.

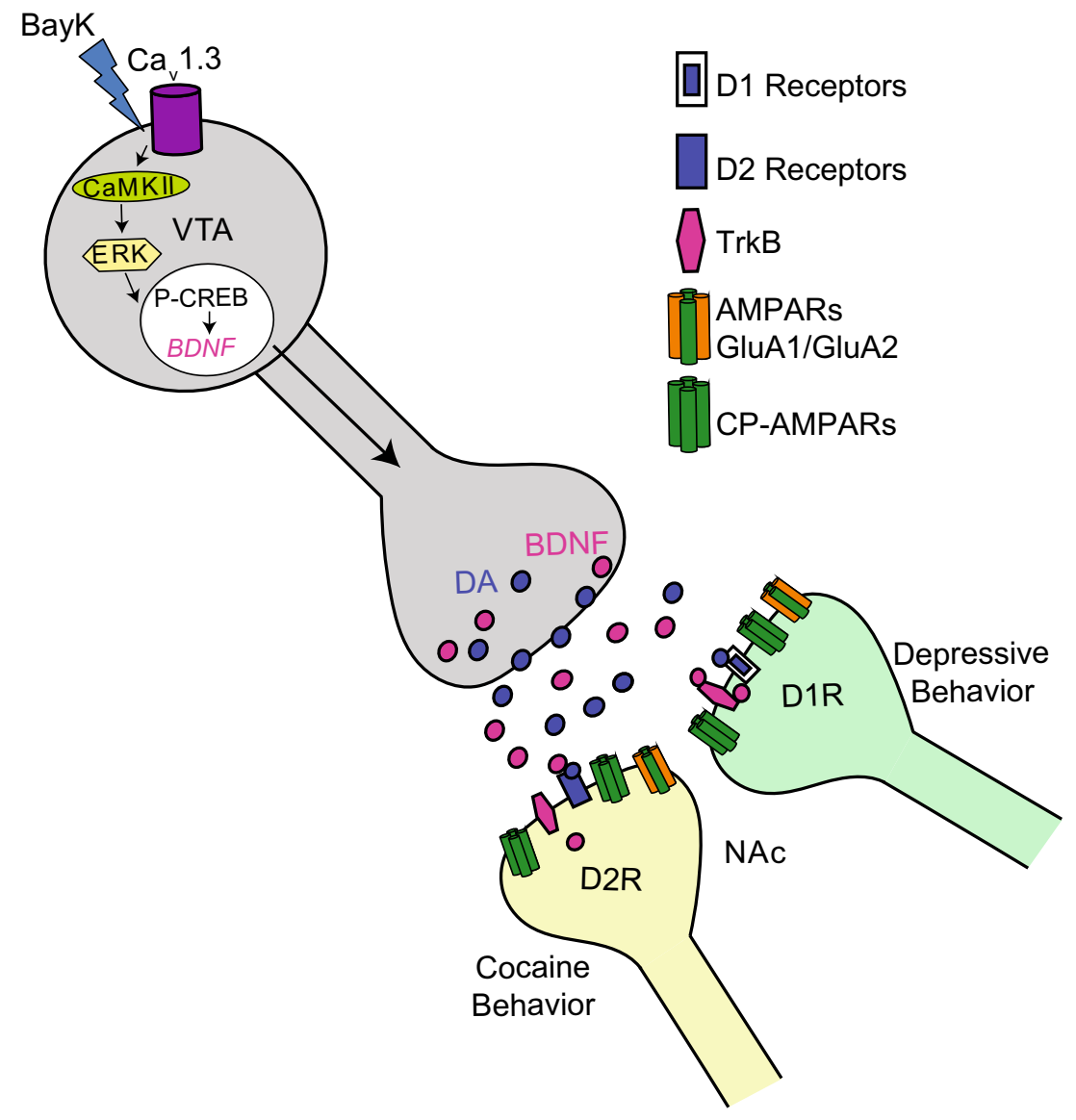

Fig. 3 Proposed mechanistic model for ventral tegmental area (VTA) $\mathrm{Ca}_{\mathrm{v}} 1.3$ activation, which leads to depressive-like and cocaine-related behaviors. VTA $\mathrm{Ca}_{\mathrm{v}} 1.3$ channel activation by BayK 8644 promotes CAM-dependent protein kinase (CaMK)II/extracellular regulated kinase (ERK)/ cAMP response element-binding protein (CREB) signaling, which results in the production of the neurotrophic factor, brain-derived neurotrophic factor (BDNF). Subsequently, BDNF gets transported from the VTA to the nucleus accumbens (NAc), which may mediate both depressive-like and cocaine behaviors, via increase in $\mathrm{Ca}^{2+}$-permeable $\alpha$-amino-3-hydroxy-5-methyl-4-isoxazolepropionic acid receptors (CPAMPARs). We propose that depressive like-behavior is mediated by a $\mathrm{BDNF} /$ tropomyosin receptor kinase $\mathrm{B}$ (TrkB) mechanism in NAc dopamine (DA) D1 receptor-expressing cells [350] and cocaine-related behaviors in NAc DA D2 receptor-expressing cells [351] 
How VTA $\mathrm{Ca}_{\mathrm{v}} 1.3$ channel activation can simultaneously promote depression- and cocaine-related behaviors remains an unanswered question. Given that $\mathrm{Ca}_{\mathrm{v}} 1.3$ activation is expected to increase VTA dopamine burst firing [327] and thus increase dopamine release in the NAc that is expected to increase cocaine behaviors but decrease depressive symptoms, opposite of what is seen in patients and animal models, dopamine alone is not sufficient to explain the emergence of both behaviors. A potential candidate that could be mediating both these behaviors is BDNF. It has been found that BDNF via its receptor, tropomyosin receptor kinase B (TrkB) in the NAc mediates both depressive behavior [366] and cocaine behaviors [367]; however, it exerts its effects on the 2 behaviors in a cell-typespecific manner. The NAc is composed of 2 primary populations: the dopamine $\mathrm{D} 1$ receptor-containing and dopamine D2 receptor-containing cells $[368,369]$. BDNF/TrkB in D1 receptor cells have been shown to mediate depressive behavior [366], whereas BDNF/TrkB in D2 receptor cells mediate cocaine behaviors [367]. As BDNF is a downstream target of LTCCs it is plausible that BDNF is generated following $\mathrm{Ca}_{\mathrm{v}} 1.3$ activation in the VTA, most likely via activation of the CaMKII/ERK/CREB pathway [325] that is transported to the NAc (Fig. 3).

\section{Conclusions}

From these studies, it is clear that dysregulation of both brainspecific LTCC isoforms $\mathrm{Ca}_{\mathrm{v}} 1.2$ and $\mathrm{Ca}_{\mathrm{v}} 1.3$ can contribute to neuropsychiatric-associated endophenotypes and that LTCC blockers have the potential for alleviating some, if not all, psychiatric symptoms resulting from CACNA $1 C$ and $C A C N A 1 D$ dysfunction. Targeted anatomical approaches and molecular studies in preclinical animal models provide evidence that dysfunction of $\mathrm{Ca}_{\mathrm{v}} 1.2$ and $\mathrm{Ca}_{\mathrm{v}} 1.3$ channels alter distinct signaling cascades in separate anatomical structures that influence behavioral outcomes. This underscores the complexity of neuropsychiatric disorders and the cell-typeand brain-region-specific influence of $C A C N A 1 C$ and possibly $C A C N A 1 D$ risk SNPs on disease symptoms. Another factor to consider as studies continue to examine potential mechanisms of $C A C N A 1 C$ - and CACNA1D-associated disorders, as well as treatment options, is the impact of secondary effects as a result of persistent dysregulated $\mathrm{Ca}^{2+}$ in neurons on neuropsychiatric symptoms. We now know that dysregulated $\mathrm{Ca}^{2+}$-mediated molecular and transcriptional gene networks [370], as well as the inability to maintain neuronal homeostasis [371], can disrupt normal development of neuronal circuits and lead to brain disease. Thus, by identifying biological pathways underlying specific symptoms and discovering novel substrates that are altered as a consequence of dysregulated $\mathrm{Ca}_{\mathrm{v}} 1.2$ and $\mathrm{Ca}_{\mathrm{v}} 1.3$ may provide better targets for therapeutics.
Required Author Forms Disclosure forms provided by the authors are available with the online version of this article.

\section{References}

1. Kabir ZD, Lee AS, Rajadhyaksha AM. L-type $\mathrm{Ca}^{2+}$ channels in mood, cognition and addiction: integrating human and rodent studies with a focus on behavioural endophenotypes. $J$ Physiol 594(20), 5823-5837 (2016).

2. Zamponi GW, Striessnig J, Koschak A, Dolphin AC. The physiology, pathology, and pharmacology of voltage-gated calcium channels and their future therapeutic potential. Pharmacol Rev 67(4), 821-870 (2015).

3. Ebert DH, Greenberg ME. Activity-dependent neuronal signalling and autism spectrum disorder. Nature 493(7432), 327-337 (2013).

4. Bhat S, Dao DT, Terrillion CE, et al. CACNA1C (Cav1.2) in the pathophysiology of psychiatric disease. Prog Neurobiol 99(1), 114 (2012).

5. Heyes S, Pratt WS, Rees E, et al. Genetic disruption of voltagegated calcium channels in psychiatric and neurological disorders. Prog Neurobiol 2015; 134:35-54.

6. Ortner NJ, Striessnig J. L-type calcium channels as drug targets in CNS disorders. Channels (Austin) 10(1), 7-13 (2016).

7. Pinggera A, Lieb A, Benedetti B, et al. CACNA1D de novo mutations in autism spectrum disorders activate Cav1.3 L-type calcium channels. Biol Psychiatry 77(9), 816-822 (2015).

8. Romme IA, de Reus MA, Ophoff RA, Kahn RS, van den Heuvel MP. Connectome disconnectivity and cortical gene expression in patients with schizophrenia. Biol Psychiatry 81(6), 495-502 (2017).

9. Gurung R, Prata DP. What is the impact of genome-wide supported risk variants for schizophrenia and bipolar disorder on brain structure and function? A systematic review. Psychol Med 45(12), 2461-2480 (2015).

10. Striessnig J, Pinggera A, Kaur G, Bock G, Tuluc P. L-type Ca(2+) channels in heart and brain. Wiley Interdiscip Rev Membr Transp Signal 3(2), 15-38 (2014).

11. Tanaka O, Sakagami H, Kondo H. Localization of mRNAs of voltage-dependent $\mathrm{Ca}(2+)$-channels: four subtypes of alpha 1and beta-subunits in developing and mature rat brain. Brain Res Mol Brain Res 30(1), 1-16 (1995).

12. Ludwig A, Flockerzi V, Hofmann F. Regional expression and cellular localization of the alphal and beta subunit of high voltage-activated calcium channels in rat brain. $J$ Neurosci 17(4), 1339-1349 (1997).

13. Herman JP, Chen KC, Booze R, Landfield PW. Up-regulation of alpha1D Ca2+ channel subunit mRNA expression in the hippocampus of aged F344 rats. Neurobiol Aging 19(6), 581-587 (1998).

14. Clark NC, Nagano N, Kuenzi FM, et al. Neurological phenotype and synaptic function in mice lacking the $\mathrm{CaV} 1.3$ alpha subunit of neuronal L-type voltage-dependent $\mathrm{Ca}^{2+}$ channels. Neuroscience 120(2), 435-442 (2003).

15. Rajadhyaksha A, Husson I, Satpute SS, et al. L-type $\mathrm{Ca}^{2+}$ channels mediate adaptation of extracellular signal-regulated kinase 1/ 2 phosphorylation in the ventral tegmental area after chronic amphetamine treatment. J Neurosci 24(34), 7464-7476 (2004).

16. Bernardi RE, Uhrig S, Spanagel R, Hansson AC. Transcriptional regulation of L-type calcium channel subtypes Cav1.2 and Cav1.3 by nicotine and their potential role in nicotine sensitization. Nicotine Tob Res 16(6), 774-785 (2014).

17. Liebmann L, Karst H, Sidiropoulou K, et al. Differential effects of corticosterone on the slow afterhyperpolarization in the basolateral 
amygdala and CA1 region: possible role of calcium channel subunits. J Neurophysiol 99(2), 958-968 (2008).

18. Brewer LD, Dowling AL, Curran-Rauhut MA, Landfield PW, Porter NM, Blalock EM. Estradiol reverses a calcium-related biomarker of brain aging in female rats. $J$ Neurosci 29(19), 60586067 (2009).

19. Daschil N, Kniewallner KM, Obermair GJ, et al. L-type calcium channel blockers and substance $\mathrm{P}$ induce angiogenesis of cortical vessels associated with beta-amyloid plaques in an Alzheimer mouse model. Neurobiol Aging 36(3), 1333-1341 (2015).

20. Uhrig S, Vandael D, Marcantoni A, et al. Differential roles for Ltype calcium channel subtypes in alcohol dependence. Neuropsychopharmacology 2017;42:1058-1069.

21. Hetzenauer A, Sinnegger-Brauns MJ, Striessnig J, Singewald N. Brain activation pattern induced by stimulation of L-type $\mathrm{Ca}^{2+}$ channels: contribution of $\mathrm{Ca}(\mathrm{V})_{1.3}$ and $\mathrm{Ca}(\mathrm{V})_{1.2}$ isoforms. Neuroscience 139(3), 1005-1015 (2006).

22. Catterall WA. Structure and regulation of voltage-gated $\mathrm{Ca}^{2+}$ channels. Annu Rev Cell Dev Biol 16, 521-555 (2000).

23. Xu W, Lipscombe D. Neuronal Ca(V)1.3alpha(1) L-type channels activate at relatively hyperpolarized membrane potentials and are incompletely inhibited by dihydropyridines. $J$ Neurosci $21(16)$, 5944-5951 (2001).

24. Lipscombe D. L-type calcium channels: highs and new lows. Circ Res 90(9), 933-935 (2002).

25. Koschak A, Reimer D, Huber I, et al. alpha 1D (Cav1.3) subunits can form l-type $\mathrm{Ca}^{2+}$ channels activating at negative voltages. $J$ Biol Chem, 276(25), 22100-22106 (2001).

26. Simms BA, Zamponi GW. Neuronal voltage-gated calcium channels: structure, function, and dysfunction. Neuron, 82(1), 24-45 (2014).

27. Calin-Jageman I, Lee A. Ca(v) 1 L-type $\mathrm{Ca}^{2+}$ channel signaling complexes in neurons. J Neurochem, 105(3), 573-583 (2008).

28. Stanika R, Campiglio M, Pinggera A, et al. Splice variants of the CaV1.3 L-type calcium channel regulate dendritic spine morphology. Sci Rep 6, 34528 (2016).

29. Zamponi GW. Targeting voltage-gated calcium channels in neurological and psychiatric diseases. Nat Rev Drug Discov 15(1), 1934 (2016).

30. Striessnig J, Ortner NJ, Pinggera A. Pharmacology of L-type calcium channels: novel drugs for old targets? Curr Mol Pharmacol 8(2), 110-122 (2015).

31. Ament SA, Szelinger S, Glusman G, et al. Rare variants in neuronal excitability genes influence risk for bipolar disorder. Proc Natl Acad Sci U S A 112(11), 3576-3581 (2015).

32. Nyegaard M, Demontis D, Foldager L, et al. CACNA1C (rs1006737) is associated with schizophrenia. Mol Psychiatry 15(2), 119-121 (2010).

33. Rao S, Yao Y, Zheng C, et al. Common variants in CACNA1C and MDD susceptibility: a comprehensive meta-analysis. Am $J$ Med Genet B Neuropsychiatr Genet 171(6), 896-903 (2016).

34. Li J, Zhao L, You Y, et al. Schizophrenia related variants in CACNA1C also confer risk of autism. PLOS ONE 10(7), e0133247 (2015).

35. Cross-Disorder Group of the Psychiatric Genomics Consortium. Identification of risk loci with shared effects on five major psychiatric disorders: a genome-wide analysis. Lancet 381(9875), 13711379 (2013).

36. Zhang F, Lupski JR. Non-coding genetic variants in human disease. Hum Mol Genet 24(R1), R102-110 (2015).

37. Roussos P, Mitchell AC, Voloudakis G, et al. A role for noncoding variation in schizophrenia. Cell Rep 9(4), 1417-1429 (2014).

38. Eckart N, Song Q, Yang R, et al. Functional characterization of schizophrenia-associated variation in CACNA1C. PLOS ONE 11(6), e0157086 (2016).
39. Bigos KL, Mattay VS, Callicott JH, et al. Genetic variation in CACNA1C affects brain circuitries related to mental illness. Arch Gen Psychiatry 67(9), 939-945 (2010).

40. Yoshimizu T, Pan JQ, Mungenast AE, et al. Functional implications of a psychiatric risk variant within CACNA1C in induced human neurons. Mol Psychiatry 20(2), 162-169 (2015).

41. Gershon ES, Grennan K, Busnello J, et al. A rare mutation of CACNA1C in a patient with bipolar disorder, and decreased gene expression associated with a bipolar-associated common SNP of CACNA1C in brain. Mol Psychiatry 19(8), 890-894 (2014).

42. International Schizophrenia C, Purcell SM, Wray NR, et al. Common polygenic variation contributes to risk of schizophrenia and bipolar disorder. Nature 460(7256), 748-752 (2009).

43. Page KM, Heblich F, Margas W, et al. $\mathrm{N}$ terminus is key to the dominant negative suppression of $\mathrm{Ca}(\mathrm{V}) 2$ calcium channels: implications for episodic ataxia type 2. J Biol Chem 285(2), 835-844 (2010).

44. Page KM, Heblich F, Davies A, et al. Dominant-negative calcium channel suppression by truncated constructs involves a kinase implicated in the unfolded protein response. J Neurosci 24(23), 5400-5409 (2004).

45. Mezghrani A, Monteil A, Watschinger K, et al. A destructive interaction mechanism accounts for dominant-negative effects of misfolded mutants of voltage-gated calcium channels. $J$ Neurosci 28(17), 4501-4511 (2008).

46. Splawski I, Timothy KW, Sharpe LM, et al. $\mathrm{Ca}(\mathrm{V}) 1.2$ calcium channel dysfunction causes a multisystem disorder including arrhythmia and autism. Cell 119(1), 19-31 (2004).

47. Gillis J, Burashnikov E, Antzelevitch C, et al. Long QT, syndactyly, joint contractures, stroke and novel CACNA1C mutation: expanding the spectrum of Timothy syndrome. Am J Med Genet A 158A(1), 182-187 (2012).

48. Splawski I, Timothy KW, Decher N, et al. Severe arrhythmia disorder caused by cardiac L-type calcium channel mutations. Proc Natl Acad Sci U S A 102(23), 8089-8096 (2005).

49. Ross J, Gedvilaite E, Badner JA, et al. A rare variant in CACNA1D segregates with 7 bipolar I disorder cases in a large pedigree. Mol Neuropsychiatry 2(3), 145-150 (2016).

50. Guan F, Li L, Qiao C, et al. Evaluation of genetic susceptibility of common variants in CACNA1D with schizophrenia in Han Chinese. Sci Rep 5, 12935 (2015).

51. Martinez-Rivera A, Hao J, Tropea TF, et al. Enhancing VTA Cav1.3 L-type $\mathrm{Ca}^{2+}$ channel activity promotes cocaine and mood-related behaviors via overlapping AMPA receptor mechanisms in the nucleus accumbens. Mol Psychiatry 2017 Feb 14 [Epub ahead of print].

52. Iossifov I, O'Roak BJ, Sanders SJ, et al. The contribution of de novo coding mutations to autism spectrum disorder. Nature 515(7526), 216-221 (2014).

53. O'Roak BJ, Vives L, Girirajan S, et al. Sporadic autism exomes reveal a highly interconnected protein network of de novo mutations. Nature 485(7397), 246-250 (2012).

54. Limpitikul WB, Dick IE, Ben-Johny M, Yue DT. An autismassociated mutation in CaV1.3 channels has opposing effects on voltage- and $\mathrm{Ca}(2+)$-dependent regulation. Sci Rep 6, 27235 (2016).

55. Olson PA, Tkatch T, Hernandez-Lopez S, et al. G-protein-coupled receptor modulation of striatal CaV1.3 L-type Ca2+ channels is dependent on a Shank-binding domain. J Neurosci 25(5), 10501062 (2005).

56. Berkefeld H, Fakler B. Repolarizing responses of BKCa-Cav complexes are distinctly shaped by their Cav subunits. $J$ Neurosci 28(33), 8238-8245 (2008).

57. Berkefeld H, Sailer CA, Bildl W, et al. BKCa-Cav channel complexes mediate rapid and localized $\mathrm{Ca} 2+$-activated $\mathrm{K}+$ signaling. Science 314(5799), 615-620 (2006). 
58. Goodnick PJ. Treatment of mania: relationship between response to verapamil and changes in plasma calcium and magnesium levels. South Med J 89(2), 225-226 (1996).

59. Wisner KL, Peindl KS, Perel JM, Hanusa BH, Piontek CM, Baab S. Verapamil treatment for women with bipolar disorder. Biol Psychiatry 51(9), 745-752 (2002).

60. Lenzi A, Marazziti D, Raffaelli S, Cassano GB. Effectiveness of the combination verapamil and chlorpromazine in the treatment of severe manic or mixed patients. Prog Neuropsychopharmacol Biol Psychiatry 19(3), 519-528 (1995).

61. Barton BM, Gitlin MJ. Verapamil in treatment-resistant mania: an open trial. J Clin Psychopharmacol 7(2), 101-103 (1987).

62. Garza-Trevino ES, Overall JE, Hollister LE. Verapamil versus lithium in acute mania. Am J Psychiatry 149(1), 121-122 (1992).

63. Giannini AJ, Taraszewski R, Loiselle RH. Verapamil and lithium in maintenance therapy of manic patients. J Clin Pharmacol 27(12), 980-982 (1987).

64. Dubovsky SL, Franks RD, Allen S. Verapamil: a new antimanic drug with potential interactions with lithium. J Clin Psychiatry 48(9), 371-372 (1987).

65. Solomon L, Williamson P. Verapamil in bipolar illness. Can J Psychiatry 31(5), 442-444 (1986)

66. Gitlin MJ, Weiss J. Verapamil as maintenance treatment in bipolar illness: a case report. J Clin Psychopharmacol 4(6), 341-343 (1984).

67. Jacques RM, Cox SJ. Verapamil in major (psychotic) depression. Br J Psychiatry 158, 124-125 (1991).

68. Dubovsky SL, Franks RD, Allen S, Murphy J. Calcium antagonists in mania: a double-blind study of verapamil. Psychiatry Res 18(4), 309-320 (1986).

69. Giannini AJ, Houser WL, Jr., Loiselle RH, Giannini MC, Price WA. Antimanic effects of verapamil. Am J Psychiatry 141(12), 1602-1603 (1984).

70. Mallinger AG, Thase ME, Haskett R, et al. Verapamil augmentation of lithium treatment improves outcome in mania unresponsive to lithium alone: preliminary findings and a discussion of therapeutic mechanisms. Bipolar Disord 10(8), 856-866 (2008).

71. Janicak PG, Sharma RP, Pandey G, Davis JM. Verapamil for the treatment of acute mania: a double-blind, placebo-controlled trial. Am J Psychiatry 155(7), 972-973 (1998).

72. Hoschl C, Kozeny J. Verapamil in affective disorders: a controlled, double-blind study. Biol Psychiatry 25(2), 128-140 (1989).

73. Ried LD, Tueth MJ, Handberg E, Kupfer S, Pepine CJ; Invest Study Group. A Study of Antihypertensive Drugs and Depressive Symptoms (SADD-Sx) in patients treated with a calcium antagonist versus an atenolol hypertension Treatment Strategy in the International Verapamil SR-Trandolapril Study (INVEST). Psychosom Med 67(3), 398-406 (2005).

74. Pazzaglia PJ, Post RM, Ketter TA, et al. Nimodipine monotherapy and carbamazepine augmentation in patients with refractory recurrent affective illness. J Clin Psychopharmacol 18(5), 404-413 (1998).

75. Pazzaglia PJ, Post RM, Ketter TA, George MS, Marangell LB. Preliminary controlled trial of nimodipine in ultra-rapid cycling affective dysregulation. Psychiatry Res 49(3), 257-272 (1993).

76. Brunet G, Cerlich B, Robert P, Dumas S, Souetre E, Darcourt G. Open trial of a calcium antagonist, nimodipine, in acute mania. Clin Neuropharmacol 13(3), 224-228 (1990).

77. Grunze H, Walden J, Wolf R, Berger M. Combined treatment with lithium and nimodipine in a bipolar I manic syndrome. Prog Neuropsychopharmacol Biol Psychiatry 20(3), 419-426 (1996).

78. Davanzo PA, Krah N, Kleiner J, McCracken J. Nimodipine treatment of an adolescent with ultradian cycling bipolar affective illness. J Child Adolesc Psychopharmacol 9(1), 51-61 (1999).

79. Caillard V. Treatment of mania using a calcium antagonist-preliminary trial. Neuropsychobiology 14(1), 23-26 (1985).
80. Silverstone PH, Birkett L. Diltiazem as augmentation therapy in patients with treatment-resistant bipolar disorder: a retrospective study. J Psychiatry Neurosci 25(3), 276-280 (2000).

81. Hullett FJ, Potkin SG, Levy AB, Ciasca R. Depression associated with nifedipine-induced calcium channel blockade. Am J Psychiatry 145(10), 1277-1279 (1988).

82. Price WA, Heil D. Treatment of the negative symptoms of schizophrenia with verapamil. Jefferson Journal of Psychiatry 5(1) (1987)

83. Price WA. Antipsychotic effects of verapamil in schizophrenia. Hillside J Clin Psychiatry 9(2), 225-230 (1987).

84. Uhr SB, Jackson K, Berger PA, Csernansky JG. Effects of verapamil administration on negative symptoms of chronic schizophrenia. Psychiatry Res 23(3), 351-352 (1988).

85. Schwartz BL, Fay-McCarthy M, Kendrick K, Rosse RB, Deutsch SI. Effects of nifedipine, a calcium channel antagonist, on cognitive function in schizophrenic patients with tardive dyskinesia. Clin Neuropharmacol 20(4), 364-370 (1997).

86. Bartko G, Horvath S, Zador G, Frecska E. Effects of adjunctive verapamil administration in chronic schizophrenic patients. Prog Neuropsychopharmacol Biol Psychiatry 15(3), 343-349 (1991).

87. Pickar D, Wolkowitz OM, Doran AR, et al. Clinical and biochemical effects of verapamil administration to schizophrenic patients. Arch Gen Psychiatry 44(2), 113-118 (1987).

88. Grebb JA, Shelton RC, Taylor EH, Bigelow LB. A negative, double-blind, placebo-controlled, clinical trial of verapamil in chronic schizophrenia. Biol Psychiatry 21(7), 691-694 (1986).

89. Stedman TJ, Whiteford HA, Eyles D, Welham JL, Pond SM. Effects of nifedipine on psychosis and tardive dyskinesia in schizophrenic patients. J Clin Psychopharmacol 11(1), 43-47 (1991).

90. Suddath RL, Straw GM, Freed WJ, Bigelow LB, Kirch DG, Wyatt RJ. A clinical trial of nifedipine in schizophrenia and tardive dyskinesia. Pharmacol Biochem Behav 39(3), $743-745$ (1991).

91. Kosten TR, Woods SW, Rosen MI, Pearsall HR. Interactions of cocaine with nimodipine: a brief report. Am J Addict 8(1), 77-81 (1999).

92. Sofuoglu M, Singha A, Kosten TR, McCance-Katz FE, Petrakis I, Oliveto A. Effects of naltrexone and isradipine, alone or in combination, on cocaine responses in humans. Pharmacol Biochem Behav 75(4), 801-808 (2003).

93. Roache JD, Johnson BA, Ait-Daoud N, et al. Effects of repeateddose isradipine on the abuse liability of cocaine. Exp Clin Psychopharmacol 13(4), 319-326 (2005).

94. Rosse RB, Alim TN, Fay-McCarthy M, et al. Nimodipine pharmacotherapeutic adjuvant therapy for inpatient treatment of cocaine dependence. Clin Neuropharmacol 17(4), 348-358 (1994).

95. Muntaner C, Kumor KM, Nagoshi C, Jaffe JH. Effects of nifedipine pretreatment on subjective and cardiovascular responses to intravenous cocaine in humans. Psychopharmacology (Berl) 105(1), 37-41 (1991).

96. Malcolm R, Brady KT, Moore J, Kajdasz D. Amlodipine treatment of cocaine dependence. J Psychoactive Drugs 31(2), 117120 (1999).

97. Johnson BA, Roache JD, Ait-Daoud N, Wells LT, Mauldin JB. Effects of isradipine on cocaine-induced subjective mood. $J$ Clin Psychopharmacol 24(2), 180-191 (2004).

98. Vaupel DB, Lange WR, London ED. Effects of verapamil on morphine-induced euphoria, analgesia and respiratory depression in humans. J Pharmacol Exp Ther 267(3), 1386-1394 (1993).

99. Hasegawa AE, Zacny JP. The influence of three L-type calcium channel blockers on morphine effects in healthy volunteers. Anesth Analg 85(3), 633-638 (1997).

100. Silverstone PH, Attenburrow MJ, Robson P. The calcium channel antagonist nifedipine causes confusion when used to treat opiate 
withdrawal in morphine-dependent patients. Int Clin Psychopharmacol 7(2), 87-90 (1992).

101. Zacny JP, Yajnik S. Effects of calcium channel inhibitors on ethanol effects and pharmacokinetics in healthy volunteers. Alcohol 10(6), 505-509 (1993).

102. Rush CR, Pazzaglia PJ. Pretreatment with isradipine, a calciumchannel blocker, does not attenuate the acute behavioral effects of ethanol in humans. Alcohol Clin Exp Res 22(2), 539-547 (1998).

103. Perez-Reyes M, White WR, Hicks RE. Interaction between ethanol and calcium channel blockers in humans. Alcohol Clin Exp Res 16(4), 769-775 (1992).

104. Altamura AC, Regazzetti MG, Porta M. Nimodipine in human alcohol withdrawal syndrome-an open study. Eur Neuropsychopharmacol 1(1), 37-40 (1990).

105. Waltereit R, Mannhardt S, Nescholta S, Maser-Gluth C, Bartsch D. Selective and protracted effect of nifedipine on fear memory extinction correlates with induced stress response. Learn Mem 15(5), 348-356 (2008)

106. Busquet P, Hetzenauer A, Sinnegger-Brauns MJ, Striessnig J, Singewald N. Role of L-type $\mathrm{Ca}^{2+}$ channel isoforms in the extinction of conditioned fear. Learn Mem 15(5), 378-386 (2008).

107. Bergson P, Lipkind G, Lee SP, Duban ME, Hanck DA. Verapamil block of T-type calcium channels. Mol Pharmacol 79(3), 411-419 (2011).

108. Zhang S, Zhou Z, Gong Q, Makielski JC, January CT. Mechanism of block and identification of the verapamil binding domain to HERG potassium channels. Circ Res 84(9), 989-998 (1999).

109. Catacuzzeno L, Trequattrini C, Petris A, Franciolini F. Mechanism of verapamil block of a neuronal delayed rectifier $\mathrm{K}$ channel: active form of the blocker and location of its binding domain. $\mathrm{Br}$ J Pharmacol 126(8), 1699-1706 (1999).

110. Harper AA, Catacuzzeno L, Trequattrini C, Petris A, Franciolini F. Verapamil block of large-conductance Ca-activated $\mathrm{K}$ channels in rat aortic myocytes. J Membr Biol 179(2), 103-111 (2001).

111. Motulsky HJ, Snavely MD, Hughes RJ, Insel PA. Interaction of verapamil and other calcium channel blockers with alpha 1- and alpha 2-adrenergic receptors. Circ Res 52(2), 226-231 (1983).

112. Marzolini C, Paus E, Buclin T, Kim RB. Polymorphisms in human MDR1 (P-glycoprotein): recent advances and clinical relevance. Clin Pharmacol Ther 75(1), 13-33 (2004).

113. Pauli-Magnus $\mathrm{C}$, von Richter $\mathrm{O}$, Burk $\mathrm{O}$, et al. Characterization of the major metabolites of verapamil as substrates and inhibitors of P-glycoprotein. J Pharmacol Exp Ther 293(2), 376-382 (2000).

114. Loscher W, Luna-Tortos C, Romermann K, Fedrowitz M. Do ATP-binding cassette transporters cause pharmacoresistance in epilepsy? Problems and approaches in determining which antiepileptic drugs are affected. Curr Pharm Des 17(26), 2808-2828 (2011).

115. Raderer M, Scheithauer W. Clinical trials of agents that reverse multidrug resistance. A literature review. Cancer 72(12), 35533563 (1993).

116. Cipriani A, Saunders K, Attenburrow MJ, et al. A systematic review of calcium channel antagonists in bipolar disorder and some considerations for their future development. Mol Psychiatry 21(10), 1324-1332 (2016).

117. Casamassima F, Hay AC, Benedetti A, Lattanzi L, Cassano GB, Perlis RH. L-type calcium channels and psychiatric disorders: a brief review. Am J Med Genet B Neuropsychiatr Genet 153B(8), 1373-1390 (2010).

118. Deisseroth K, Heist EK, Tsien RW. Translocation of calmodulin to the nucleus supports CREB phosphorylation in hippocampal neurons. Nature 392(6672), 198-202 (1998).

119. Ma H, Groth RD, Cohen SM, et al. gammaCaMKII shuttles $\mathrm{Ca}(2)(+) / \mathrm{CaM}$ to the nucleus to trigger CREB phosphorylation and gene expression. Cell 159(2), 281-294 (2014).
120. Wheeler DG, Barrett CF, Groth RD, Safa P, Tsien RW. CaMKII locally encodes L-type channel activity to signal to nuclear CREB in excitation-transcription coupling. J Cell Biol 183(5), 849-863 (2008).

121. Cohen SM, Li B, Tsien RW, Ma H. Evolutionary and functional perspectives on signaling from neuronal surface to nucleus. Biochem Biophys Res Commun 460(1), 88-99 (2015).

122. Ma H, Li B, Tsien RW. Distinct roles of multiple isoforms of CaMKII in signaling to the nucleus. Biochim Biophys Acta 1853(9), 1953-1957 (2015).

123. Wu GY, Deisseroth K, Tsien RW. Activity-dependent CREB phosphorylation: convergence of a fast, sensitive calmodulin kinase pathway and a slow, less sensitive mitogen-activated protein kinase pathway. Proc Natl Acad Sci U S A 98(5), 2808-2813 (2001).

124. Wu GY, Deisseroth K, Tsien RW. Spaced stimuli stabilize MAPK pathway activation and its effects on dendritic morphology. Nat Neurosci 4(2), 151-158 (2001).

125. Dolmetsch RE, Pajvani U, Fife K, Spotts JM, Greenberg ME. Signaling to the nucleus by an L-type calcium channelcalmodulin complex through the MAP kinase pathway. Science 294(5541), 333-339 (2001).

126. Hofmann HA. Functional genomics of neural and behavioral plasticity. J Neurobiol 54(1), 272-282 (2003).

127. Ortega-Martinez S. A new perspective on the role of the CREB family of transcription factors in memory consolidation via adult hippocampal neurogenesis. Front Mol Neurosci 8, 46 (2015).

128. Nestler EJ. Cellular basis of memory for addiction. Dialogues Clin Neurosci 15(4), 431-443 (2013).

129. Harrington AJ, Raissi A, Rajkovich K, et al. MEF2C regulates cortical inhibitory and excitatory synapses and behaviors relevant to neurodevelopmental disorders. Elife 2016;5:e20059.

130. Lombardi LM, Baker SA, Zoghbi HY. MECP2 disorders: from the clinic to mice and back. J Clin Invest 125(8), 2914-2923 (2015).

131. Mao Z, Bonni A, Xia F, Nadal-Vicens M, Greenberg ME. Neuronal activity-dependent cell survival mediated by transcription factor MEF2. Science 286(5440), 785-790 (1999).

132. Tian Y, Voineagu I, Pasca SP, et al. Alteration in basal and depolarization induced transcriptional network in iPSC derived neurons from Timothy syndrome. Genome Med 6(10), 75 (2014).

133. Chen WG, Chang Q, Lin Y, et al. Derepression of BDNF transcription involves calcium-dependent phosphorylation of $\mathrm{MeCP} 2$. Science 302(5646), 885-889 (2003).

134. Pfeiffer BE, Zang T, Wilkerson JR, et al. Fragile X mental retardation protein is required for synapse elimination by the activitydependent transcription factor MEF2. Neuron 66(2), 191-197 (2010).

135. Murphy JG, Sanderson JL, Gorski JA, et al. AKAP-anchored PKA maintains neuronal L-type calcium channel activity and NFAT transcriptional signaling. Cell Rep 7(5), 1577-1588 (2014).

136. Graef IA, Mermelstein PG, Stankunas K, et al. L-type calcium channels and GSK-3 regulate the activity of NF-ATc4 in hippocampal neurons. Nature 401(6754), 703-708 (1999).

137. Nurnberger JI, Jr., Koller DL, Jung J, et al. Identification of pathways for bipolar disorder: a meta-analysis. JAMA Psychiatry 71(6), 657-664 (2014).

138. Darby MM, Yolken RH, Sabunciyan S. Consistently altered expression of gene sets in postmortem brains of individuals with major psychiatric disorders. Transl Psychiatry 6(9), e890 (2016).

139. Hertzberg L, Katsel P, Roussos P, Haroutunian V, Domany E. Integration of gene expression and GWAS results supports involvement of calcium signaling in Schizophrenia. Schizophr Res, 164(1-3), 92-99 (2015).

140. Wen Y, Alshikho MJ, Herbert MR. Pathway network analyses for autism reveal multisystem involvement, major overlaps with other 
diseases and convergence upon MAPK and calcium signaling. PLOS ONE 11(4), e0153329 (2016).

141. Focking M, Lopez LM, English JA, et al. Proteomic and genomic evidence implicates the postsynaptic density in schizophrenia. Mol Psychiatry 20(4), 424-432 (2015).

142. Focking M, Dicker P, Lopez LM, et al. Proteomic analysis of the postsynaptic density implicates synaptic function and energy pathways in bipolar disorder. Transl Psychiatry 6(11), e959 (2016).

143. Pinto D, Delaby E, Merico D, et al. Convergence of genes and cellular pathways dysregulated in autism spectrum disorders. Am J Hum Genet 94(5), 677-694 (2014).

144. Nho K, Ramanan VK, Horgusluoglu E, et al. Comprehensive gene- and pathway-based analysis of depressive symptoms in older adults. J Alzheimers Dis 45(4), 1197-1206 (2015).

145. Kerner B, Rao AR, Christensen B, Dandekar S, Yourshaw M, Nelson SF. Rare genomic variants link bipolar disorder with anxiety disorders to CREB-regulated intracellular signaling pathways. Front Psychiatry 4, 154 (2013).

146. Wek RC, Cavener DR. Translational control and the unfolded protein response. Antioxid Redox Signal 9(12), 2357-2371 (2007).

147. Krey JF, Pașca SP, Shcheglovitov A, et al. Timothy syndrome is associated with activity-dependent dendritic retraction in rodent and human neurons. Nat Neurosci 16(2), 201-209 (2013).

148. Pasca SP, Portmann T, Voineagu I, et al. Using iPSC-derived neurons to uncover cellular phenotypes associated with Timothy syndrome. Nat Med 17(12), 1657-1662 (2011).

149. Lee AS, De Jesus-Cortes H, Kabir ZD, et al. The neuropsychiatric disease-associated gene cacna1c mediates survival of young hippocampal neurons. eNeuro 3(2) (2016).

150. Kabir ZD, Che A, D F et al. Rescue of impaired sociability and anxietylike behavior in adult cacnal cdeficient mice by pharmacologically targeting eIF2 $\alpha$. Molecular Psychiatry (2017, in press).

151. Mullins C, Fishell G, Tsien RW. Unifying views of autism spectrum disorders: a consideration of autoregulatory feedback loops. Neuron 89(6), 1131-1156 (2016).

152. Kabir ZD, Lee AS, Burgdorf CE, et al. Cacnalc in the prefrontal cortex regulates depression-related behaviors via REDD1. Neuropsychopharmacology 2017 Jan 4 [Epub ahead of print].

153. Lee AS, Ra S, Rajadhyaksha AM, et al. Forebrain elimination of cacna1c mediates anxiety-like behavior in mice. Mol Psychiatry 17(11), 1054-1055 (2012).

154. Hess P, Lansman JB, Tsien RW. Different modes of Ca channel gating behaviour favoured by dihydropyridine $\mathrm{Ca}$ agonists and antagonists. Nature 311(5986), 538-544 (1984).

155. Seisenberger $\mathrm{C}$, Specht $\mathrm{V}$, Welling A et al. Functional embryonic cardiomyocytes after disruption of the L-type alpha1C (Cav1.2) calcium channel gene in the mouse. J Biol Chem 275(50), 3919339199 (2000).

156. Goonasekera SA, Hammer K, Auger-Messier M, et al. Decreased cardiac L-type $\mathrm{Ca}(2)(+)$ channel activity induces hypertrophy and heart failure in mice. J Clin Invest $122(1)$, 280-290 (2012)

157. Dao DT, Mahon PB, Cai X, et al. Mood disorder susceptibility gene CACNA1C modifies mood-related behaviors in mice and interacts with sex to influence behavior in mice and diagnosis in humans. Biol Psychiatry 68(9), 801-810 (2010).

158. Bavley CC, Fischer DK, Rizzo BK, Rajadhyaksha AM. Cav1.2 channels mediate persistent chronic stress-induced behavioral deficits that are associated with prefrontal cortex activation of the p25/Cdk5-glucocorticoid receptor pathway. Neurobiol Stress 7, 27-37 (2017)

159. Sinnegger-Brauns MJ, Hetzenauer A, Huber IG, et al. Isoformspecific regulation of mood behavior and pancreatic beta cell and cardiovascular function by L-type $\mathrm{Ca} 2+$ channels. $J$ Clin Invest 113(10), 1430-1439 (2004).
160. Giordano TP, Tropea TF, Satpute SS, et al. Molecular switch from L-type Ca v 1.3 to $\mathrm{Ca}$ v $1.2 \mathrm{Ca}^{2+}$ channel signaling underlies longterm psychostimulant-induced behavioral and molecular plasticity. J Neurosci 30(50), 17051-17062 (2010).

161. Schierberl K, Hao J, Tropea TF, et al. Cav1.2 L-type $\mathrm{Ca}(2)(+)$ channels mediate cocaine-induced GluA1 trafficking in the nucleus accumbens, a long-term adaptation dependent on ventral tegmental area Ca(v)1.3 channels. J Neurosci 31(38), 13562-13575 (2011).

162. Kessler RC, Aguilar-Gaxiola S, Alonso J, et al. The global burden of mental disorders: an update from the WHO World Mental Health (WMH) surveys. Epidemiol Psichiatr Soc 18(1), 23-33 (2009).

163. Erk S, Meyer-Lindenberg A, Linden DE, et al. Replication of brain function effects of a genome-wide supported psychiatric risk variant in the CACNA1C gene and new multi-locus effects. Neuroimage 94, 147-154 (2014).

164. Erk S, Meyer-Lindenberg A, Schnell K, et al. Brain function in carriers of a genome-wide supported bipolar disorder variant. Arch Gen Psychiatry 67(8), 803-811 (2010).

165. Roussos P, Giakoumaki SG, Georgakopoulos A, Robakis NK, Bitsios P. The CACNA1C and ANK3 risk alleles impact on affective personality traits and startle reactivity but not on cognition or gating in healthy males. Bipolar Disord 13(3), 250-259 (2011).

166. Wang F, McIntosh AM, He Y, Gelernter J, Blumberg HP. The association of genetic variation in CACNA1C with structure and function of a frontotemporal system. Bipolar Disord 13(7-8), 696700 (2011).

167. Dima D, Jogia J, Collier D, Vassos E, Burdick KE, Frangou S. Independent modulation of engagement and connectivity of the facial network during affect processing by CACNA1C and ANK3 risk genes for bipolar disorder. JAMA Psychiatry 70(12), 13031311 (2013).

168. Bader PL, Faizi M, Kim LH, et al. Mouse model of Timothy syndrome recapitulates triad of autistic traits. Proc Natl Acad Sci US A 108(37), 15432-15437 (2011).

169. Kennedy DP, Adolphs R. The social brain in psychiatric and neurological disorders. Trends Cogn Sci 16(11), 559-572 (2012).

170. American Psychiatric Association. Diagnostic and statistical manual of mental disorders (5th ed.), (2013). Arlington, VA: American Psychiatric Association.

171. Grant BF, Hasin DS, Blanco C, et al. The epidemiology of social anxiety disorder in the United States: results from the National Epidemiologic Survey on Alcohol and Related Conditions. $J$ Clin Psychiatry 66(11), 1351-1361 (2005).

172. Hidalgo RB, Barnett SD, Davidson JR. Social anxiety disorder in review: two decades of progress. Int $J$ Neuropsychopharmacol 4(3), 279-298 (2001).

173. Allsop SA, Vander Weele CM, Wichmann R, Tye KM. Optogenetic insights on the relationship between anxiety-related behaviors and social deficits. Front Behav Neurosci 8, 241 (2014).

174. Workman ER, Niere F, Raab-Graham KF. mTORC1-dependent protein synthesis underlying rapid antidepressant effect requires $\mathrm{GABA}_{\mathrm{B}} \mathrm{R}$ signaling. Neuropharmacology 73, 192-203 (2013).

175. Nandagopal N, Roux PP. Regulation of global and specific mRNA translation by the mTOR signaling pathway. Translation 3(1), e983402 (2015).

176. Costa-Mattioli M, Monteggia LM. mTOR complexes in neurodevelopmental and neuropsychiatric disorders. Nat Neurosci 16(11), 1537-1543 (2013).

177. Gkogkas CG, Khoutorsky A, Ran I, et al. Autism-related deficits via dysregulated eIF4E-dependent translational control. Nature 493(7432), 371-377 (2013).

178. Santini E, Huynh TN, MacAskill AF, et al. Exaggerated translation causes synaptic and behavioural aberrations associated with autism. Nature 493(7432), 411-415 (2013). 
179. Sato A, Kasai S, Kobayashi T, et al. Rapamycin reverses impaired social interaction in mouse models of tuberous sclerosis complex. Nat Commun 3, 1292 (2012).

180. Hwang SK, Lee JH, Yang JE, et al. Everolimus improves neuropsychiatric symptoms in a patient with tuberous sclerosis carrying a novel TSC2 mutation. Mol Brain 9(1), 56 (2016).

181. Ricciardi S, Boggio EM, Grosso S, et al. Reduced AKT/mTOR signaling and protein synthesis dysregulation in a Rett syndrome animal model. Hum Mol Genet 20(6), 1182-1196 (2011).

182. Sidrauski C, McGeachy AM, Ingolia NT, Walter P. The small molecule ISRIB reverses the effects of eIF2alpha phosphorylation on translation and stress granule assembly. Elife 4 (2015).

183. Zimmerman HR, Beckelman B, Yang W, Ma T. Interactions between the eIF2a and mTORC1 signaling pathways. Program No. 126.02. 2016 Neuroscience Meeting Planner, San Diego, Society for Neuroscience, Online (2016).

184. Sidrauski C, Acosta-Alvear D, Khoutorsky A, et al. Pharmacological brake-release of mRNA translation enhances cognitive memory. Elife 2, e00498 (2013).

185. Hai T, Hartman MG. The molecular biology and nomenclature of the activating transcription factor/cAMP responsive element binding family of transcription factors: activating transcription factor proteins and homeostasis. Gene 273(1), 1-11 (2001).

186. Mogilnicka E, Czyrak A, Maj J. Dihydropyridine calcium channel antagonists reduce immobility in the mouse behavioral despair test; antidepressants facilitate nifedipine action. Eur J Pharmacol 138(3), 413-416 (1987).

187. Cohen C, Perrault G, Sanger DJ. Assessment of the antidepressantlike effects of L-type voltage-dependent channel modulators. Behav Pharmacol 8(6-7), 629-638 (1997).

188. Li N, Lee B, Liu RJ, et al. mTOR-dependent synapse formation underlies the rapid antidepressant effects of NMDA antagonists. Science 329(5994), 959-964 (2010).

189. Mogilnicka E, Czyrak A, Maj J. BAY K 8644 enhances immobility in the mouse behavioral despair test, an effect blocked by nifedipine. Eur J Pharmacol 151(2), 307-311 (1988).

190. Ota KT, Liu RJ, Voleti B, et al. REDD1 is essential for stressinduced synaptic loss and depressive behavior. Nat Med 20(5), 531-535 (2014).

191. Magno LA, Santana CV, Sacramento EK, et al. Genetic variations in FOXO3A are associated with Bipolar Disorder without confering vulnerability for suicidal behavior. $J$ Affect Disord 133(3), 633-637 (2011).

192. Wang H, Quirion R, Little PJ, et al. Forkhead box O transcription factors as possible mediators in the development of major depression. Neuropharmacology 99, 527-537 (2015).

193. Polter A, Yang S, Zmijewska AA et al. Forkhead box, class O transcription factors in brain: regulation and behavioral manifestation. Biol Psychiatry 65(2), 150-159 (2009).

194. Mao Z, Liu L, Zhang R, Li X. Lithium reduces FoxO3a transcriptional activity by decreasing its intracellular content. Biol Psychiatry 62(12), 1423-1430 (2007).

195. Millan MJ, Agid Y, Brune M, et al. Cognitive dysfunction in psychiatric disorders: characteristics, causes and the quest for improved therapy. Nat Rev Drug Discov 11(2), 141-168 (2012).

196. White JA, McKinney BC, John MC, Powers PA, Kamp TJ, Murphy GG. Conditional forebrain deletion of the L-type calcium channel Ca V 1.2 disrupts remote spatial memories in mice. Learn Mem 15(1), 1-5 (2008).

197. Temme SJ, Bell RZ, Fisher GL, Murphy GG. Deletion of the mouse homolog of CACNA1C disrupts discrete forms of hippocampal-dependent memory and neurogenesis within the dentate gyrus. eNeuro, 3(6) (2016).

198. Moosmang S, Haider N, Klugbauer N, et al. Role of hippocampal Cav1.2 Ca2+ channels in NMDA receptor-independent synaptic plasticity and spatial memory. $J$ Neurosci $25(43), 9883-9892$ (2005).

199. Nicoll RA. A brief history of long-term potentiation. Neuron 93(2), 281-290 (2017).

200. Yau SY, Li A, So KF. Involvement of adult hippocampal neurogenesis in learning and forgetting. Neural Plast 2015, 717958 (2015).

201. Deng W, Aimone JB, Gage FH. New neurons and new memories: how does adult hippocampal neurogenesis affect learning and memory? Nat Rev Neurosci 11(5), 339-350 (2010).

202. Waltz JA. The neural underpinnings of cognitive flexibility and their disruption in psychotic illness. Neuroscience 345, 203-217 (2017).

203. LeDoux JE. Emotion circuits in the brain. Annu Rev Neurosci 23, 155-184 (2000).

204. Pezze MA, Feldon J. Mesolimbic dopaminergic pathways in fear conditioning. Prog Neurobiol 74(5), 301-320 (2004).

205. Singewald N, Schmuckermair C, Whittle N, Holmes A, Ressler KJ. Pharmacology of cognitive enhancers for exposure-based therapy of fear, anxiety and trauma-related disorders. Pharmacol Ther 149, 150-190 (2015).

206. Phillips ML, Drevets WC, Rauch SL, Lane R. Neurobiology of emotion perception I: The neural basis of normal emotion perception. Biol Psychiatry 54(5), 504-514 (2003).

207. Cain CK, Blouin AM, Barad M. L-type voltage-gated calcium channels are required for extinction, but not for acquisition or expression, of conditional fear in mice. $J$ Neurosci 22(20), 91139121 (2002).

208. Bauer EP, Schafe GE, LeDoux JE. NMDA receptors and L-type voltage-gated calcium channels contribute to long-term potentiation and different components of fear memory formation in the lateral amygdala. J Neurosci 22(12), 5239-5249 (2002).

209. Davis SE, Bauer EP. L-type voltage-gated calcium channels in the basolateral amygdala are necessary for fear extinction. $J$ Neurosci 32(39), 13582-13586 (2012).

210. Langwieser N, Christel CJ, Kleppisch T, Hofmann F, Wotjak CT, Moosmang S. Homeostatic switch in hebbian plasticity and fear learning after sustained loss of Cav1.2 calcium channels. $J$ Neurosci 30(25), 8367-8375 (2010).

211. McKinney BC, Sze W, White JA, Murphy GG. L-type voltagegated calcium channels in conditioned fear: a genetic and pharmacological analysis. Learn Mem 15(5), 326-334 (2008).

212. Barad M, Blouin AM, Cain CK. Like extinction, latent inhibition of conditioned fear in mice is blocked by systemic inhibition of Ltype voltage-gated calcium channels. Learn Mem 11(5), 536-539 (2004).

213. Shinnick-Gallagher P, McKernan MG, Xie J, Zinebi F. L-type voltage-gated calcium channels are involved in the in vivo and in vitro expression of fear conditioning. Ann N Y Acad Sci 985, 135-149 (2003).

214. Weisskopf MG, Bauer EP, LeDoux JE. L-type voltage-gated calcium channels mediate NMDA-independent associative long-term potentiation at thalamic input synapses to the amygdala. $J$ Neurosci 19(23), 10512-10519 (1999).

215. Lee O, Lee CJ, Choi S. Induction mechanisms for L-LTP at thalamic input synapses to the lateral amygdala: requirement of mGluR5 activation. Neuroreport 13(5), 685-691 (2002).

216. Pape HC, Pare D. Plastic synaptic networks of the amygdala for the acquisition, expression, and extinction of conditioned fear. Physiol Rev 90(2), 419-463 (2010).

217. Meis S, Endres T, Lessmann V. Postsynaptic BDNF signalling regulates long-term potentiation at thalamo-amygdala afferents. $J$ Physiol 590(1), 193-208 (2012).

218. Ghosh A, Carnahan J, Greenberg ME. Requirement for BDNF in activity-dependent survival of cortical neurons. Science 263(5153), 1618-1623 (1994). 
219. Rattiner LM, Davis M, French CT, Ressler KJ. Brain-derived neurotrophic factor and tyrosine kinase receptor B involvement in amygdala-dependent fear conditioning. J Neurosci 24(20), 47964806 (2004).

220. Ou LC, Gean PW. Transcriptional regulation of brain-derived neurotrophic factor in the amygdala during consolidation of fear memory. Mol Pharmacol 72(2), 350-358 (2007).

221. See V, Boutillier AL, Bito H, Loeffler JP. Calcium/calmodulindependent protein kinase type IV (CaMKIV) inhibits apoptosis induced by potassium deprivation in cerebellar granule neurons. FASEB J 15(1), 134-144 (2001).

222. Tao X, Finkbeiner S, Arnold DB, Shaywitz AJ, Greenberg ME. $\mathrm{Ca}^{2+}$ influx regulates BDNF transcription by a CREB family transcription factor-dependent mechanism. Neuron 20(4), 709-726 (1998).

223. Pieper AA, Wu X, Han TW, et al. The neuronal PAS domain protein 3 transcription factor controls FGF-mediated adult hippocampal neurogenesis in mice. Proc Natl Acad Sci U S A 102(39), 14052-14057 (2005).

224. Pickard BS, Pieper AA, Porteous DJ, Blackwood DH, Muir WJ. The NPAS3 gene- emerging evidence for a role in psychiatric illness. Ann Med 38(6), 439-448 (2006).

225. Reif A, Schmitt A, Fritzen S, Lesch KP. Neurogenesis and schizophrenia: dividing neurons in a divided mind? Eur Arch Psychiatry Clin Neurosci 257(5), 290-299 (2007).

226. Pickard B. Progress in defining the biological causes of schizophrenia. Exp Rev Mol Med 13, e25 (2011).

227. Wu Q, Li Y, Xiao B. DISC1-related signaling pathways in adult neurogenesis of the hippocampus. Gene 518(2), 223-230 (2013).

228. Schreiber R, Newman-Tancredi A. Improving cognition in schizophrenia with antipsychotics that elicit neurogenesis through 5HT(1A) receptor activation. Neurobiol Learn Mem 110, 72-80 (2014).

229. Ohira K, Kobayashi K, Toyama K, et al. Synaptosomal-associated protein 25 mutation induces immaturity of the dentate granule cells of adult mice. Mol Brain 6, 12 (2013).

230. Le Strat Y, Ramoz N, Gorwood P. The role of genes involved in neuroplasticity and neurogenesis in the observation of a geneenvironment interaction (GxE) in schizophrenia. Curr Mol Med 9(4), 506-518 (2009).

231. Knight HM, Walker R, James R, et al. GRIK4/KA1 protein expression in human brain and correlation with bipolar disorder risk variant status. Am J Med Genet B Neuropsychiatr Genet 159B(1), 21-29 (2012)

232. Serafini G, Hayley S, Pompili M, et al. Hippocampal neurogenesis, neurotrophic factors and depression: possible therapeutic targets? CNS Neurol Disord Drug Targets 13(10), 17081721 (2014).

233. Walker AK, Rivera PD, Wang Q, et al. The P7C3 class of neuroprotective compounds exerts antidepressant efficacy in mice by increasing hippocampal neurogenesis. Mol Psychiatry 20(4), 500-508 (2015).

234. Amiri A, Cho W, Zhou J, et al. Pten deletion in adult hippocampal neural stem/progenitor cells causes cellular abnormalities and alters neurogenesis. J Neurosci 32(17), 5880-5890 (2012).

235. Jolly LA, Homan CC, Jacob R, Barry S, Gecz J. The UPF3B gene, implicated in intellectual disability, autism, ADHD and childhood onset schizophrenia regulates neural progenitor cell behaviour and neuronal outgrowth. Hum Mol Genet 22(23), 4673-4687 (2013).

236. Cope EC, Briones BA, Brockett AT, et al. Immature neurons and radial glia, but not astrocytes or microglia, are altered in adult Cntnap2 and Shank3 mice, models of autism. eNeuro, 3(5) (2016).

237. Chen Z, Li X, Zhou J, et al. Accumulated quiescent neural stem cells in adult hippocampus of the mouse model for the MECP2 duplication syndrome. Sci Rep 7, 41701 (2017).
238. Dabe EC, Majdak P, Bhattacharya TK, Miller DS, Rhodes JS. Chronic D-amphetamine administered from childhood to adulthood dose-dependently increases the survival of new neurons in the hippocampus of male C57BL/6J mice. Neuroscience 231, 125-135 (2013).

239. Sahay A, Scobie KN, Hill AS, et al. Increasing adult hippocampal neurogenesis is sufficient to improve pattern separation. Nature 472(7344), 466-470 (2011).

240. Hill AS, Sahay A, Hen R. Increasing adult hippocampal neurogenesis is sufficient to reduce anxiety and depression-like behaviors. Neuropsychopharmacology 40(10), 2368-2378 (2015).

241. Deisseroth K, Singla S, Toda H, Monje M, Palmer TD, Malenka RC. Excitation-neurogenesis coupling in adult neural stem/ progenitor cells. Neuron 42(4), 535-552 (2004).

242. Teh DB, Ishizuka T, Yawo H. Regulation of later neurogenic stages of adult-derived neural stem/progenitor cells by L-type $\mathrm{Ca}^{2+}$ channels. Dev Growth Differ 56(8), 583-594 (2014).

243. Pieper AA, Xie S, Capota E, et al. Discovery of a proneurogenic, neuroprotective chemical. Cell 142(1), 39-51 (2010).

244. Marschallinger J, Sah A, Schmuckermair C, et al. The L-type calcium channel Cav1.3 is required for proper hippocampal neurogenesis and cognitive functions. Cell Calcium 58(6), 606616 (2015).

245. Duman RS, Monteggia LM. A neurotrophic model for stressrelated mood disorders. Biol Psychiatry 59(12), 1116-1127 (2006).

246. Hill JL, Martinowich K. Activity-dependent signaling: influence on plasticity in circuits controlling fear-related behavior. Curr Opin Neurobiol 36, 59-65 (2016).

247. Martinowich K, Manji H, Lu B. New insights into BDNF function in depression and anxiety. Nat Neurosci 10(9), 1089-1093 (2007).

248. Lu B, Martinowich K. Cell biology of BDNF and its relevance to schizophrenia. Novartis Foundation symposium, 289, 119-129; discussion 129-135, 193-115 (2008).

249. Zheng F, Zhou X, Luo Y, Xiao H, Wayman G, Wang H. Regulation of brain-derived neurotrophic factor exon IV transcription through calcium responsive elements in cortical neurons. PLOS ONE 6(12), e28441 (2011).

250. Smrt RD, Eaves-Egenes J, Barkho BZ, et al. Mecp2 deficiency leads to delayed maturation and altered gene expression in hippocampal neurons. Neurobiol Dis 27(1), 77-89 (2007).

251. Li H, Zhong X, Chau KF, et al. Cell cycle-linked MeCP2 phosphorylation modulates adult neurogenesis involving the Notch signalling pathway. Nat Commun 5, 5601 (2014).

252. Chen WG, West AE, Tao X, et al. Upstream stimulatory factors are mediators of $\mathrm{Ca} 2+$-responsive transcription in neurons. $J$ Neurosci 23(7), 2572-2581 (2003).

253. Tao J, Hu K, Chang Q, et al. Phosphorylation of MeCP2 at Serine 80 regulates its chromatin association and neurological function. Proc Natl Acad Sci U S A 106(12), 4882-4887 (2009).

254. Tao X, West AE, Chen WG, Corfas G, Greenberg ME. A calciumresponsive transcription factor, $\mathrm{CaRF}$, that regulates neuronal activity-dependent expression of BDNF. Neuron 33(3), 383-395 (2002).

255. Chao HT, Zoghbi HY. The yin and yang of MeCP2 phosphorylation. Proc Natl Acad Sci U S A 106(12), 4577-4578 (2009).

256. Cunha C, Brambilla R, Thomas KL. A simple role for BDNF in learning and memory? Front Mol Neurosci 3, 1 (2010).

257. Castren E, Kojima M. Brain-derived neurotrophic factor in mood disorders and antidepressant treatments. Neurobiol Dis 97(Pt B), 119-126 (2017).

258. Kemp SW, Szynkaruk M, Stanoulis KN, et al. Pharmacologic rescue of motor and sensory function by the neuroprotective compound P7C3 following neonatal nerve injury. Neuroscience 284, 202-216 (2015). 
259. Tesla R, Wolf HP, Xu P, et al. Neuroprotective efficacy of aminopropyl carbazoles in a mouse model of amyotrophic lateral sclerosis. Proc Natl Acad Sci U S A 109(42), 17016-17021 (2012).

260. De Jesus-Cortes H, Xu P, Drawbridge J et al. Neuroprotective efficacy of aminopropyl carbazoles in a mouse model of Parkinson disease. Proc Natl Acad Sci U S A 109(42), 1701017015 (2012).

261. Blaya MO, Bramlett HM, Naidoo J, Pieper AA, Dietrich WD. Neuroprotective efficacy of a proneurogenic compound after traumatic brain injury. J Neurotrauma 31(5), 476-486 (2014).

262. Yin TC, Britt JK, De Jesus-Cortes H, et al. P7C3 neuroprotective chemicals block axonal degeneration and preserve function after traumatic brain injury. Cell Rep 8(6), 1731-1740 (2014).

263. Dutca LM, Stasheff SF, Hedberg-Buenz A, et al. Early detection of subclinical visual damage after blast-mediated TBI enables prevention of chronic visual deficit by treatment with P7C3-S243. Invest Ophthalmol Vis Sci 55(12), 8330-8341 (2014).

264. De Jesus-Cortes H, Miller AD, Britt JK, et al. Protective efficacy of P7C3-S243 in the 6-hydroxydopamine model of Parkinson's disease. NPJ Parkinsons Dis 1 (2015).

265. Naidoo J, De Jesus-Cortes H, Huntington P, et al. Discovery of a neuroprotective chemical, (S)-N-(3-(3,6-dibromo-9H-carbazol-9yl)-2-fluoropropyl)-6-methoxypyridin-2-amine [(-)-P7C3-S243], with improved druglike properties. J Med Chem 57(9), 37463754 (2014).

266. Pieper AA, McKnight SL, Ready JM. P7C3 and an unbiased approach to drug discovery for neurodegenerative diseases. Chem Soc Rev 43(19), 6716-6726 (2014).

267. Gao R, Penzes P. Common mechanisms of excitatory and inhibitory imbalance in schizophrenia and autism spectrum disorders. Curr Mol Med 15(2), 146-167 (2015).

268. Bicks LK, Koike H, Akbarian S, Morishita H. Prefrontal cortex and social cognition in mouse and man. Front Psychol 6, 1805 (2015).

269. Nelson SB, Valakh V. Excitatory/inhibitory balance and circuit homeostasis in autism spectrum disorders. Neuron 87(4), 684698 (2015)

270. Frank CA. How voltage-gated calcium channels gate forms of homeostatic synaptic plasticity. Front Cell Neurosci 8, 40 (2014).

271. Gong B, Wang H, Gu S, Heximer SP, Zhuo M. Genetic evidence for the requirement of adenylyl cyclase 1 in synaptic scaling of forebrain cortical neurons. Eur J Neurosci 26(2), 275-288 (2007).

272. Saliba RS, Gu Z, Yan Z, Moss SJ. Blocking L-type voltage-gated $\mathrm{Ca}^{2+}$ channels with dihydropyridines reduces gammaaminobutyric acid type A receptor expression and synaptic inhibition. J Biol Chem 284(47), 32544-32550 (2009).

273. Hirtz JJ, Braun N, Griesemer D, et al. Synaptic refinement of an inhibitory topographic map in the auditory brainstem requires functional Cav1.3 calcium channels. J Neurosci 32(42), 1460214616 (2012).

274. Busquet P, Nguyen NK, Schmid E, et al. CaV1.3 L-type Ca2+ channels modulate depression-like behaviour in mice independent of deaf phenotype. Int J Neuropsychopharmacol 13(4), 499-513 (2010).

275. Platzer J, Engel J, Schrott-Fischer A, et al. Congenital deafness and sinoatrial node dysfunction in mice lacking class D L-type $\mathrm{Ca}^{2+}$ channels. Cell 102(1), 89-97 (2000).

276. McKinney BC, Murphy GG. The L-Type voltage-gated calcium channel Cav1.3 mediates consolidation, but not extinction, of contextually conditioned fear in mice. Learn Mem 13(5), 584-589 (2006).

277. McKinney BC, Sze W, Lee B, Murphy GG. Impaired long-term potentiation and enhanced neuronal excitability in the amygdala of Ca(V)1.3 knockout mice. Neurobiol Learn Mem 92(4), 519-528 (2009).
278. Hell JW, Westenbroek RE, Warner C, et al. Identification and differential subcellular localization of the neuronal class $\mathrm{C}$ and class D L-type calcium channel alpha 1 subunits. J Cell Biol 123(4), 949-962 (1993).

279. Lancaster TM, Heerey EA, Mantripragada K, Linden DE. CACNA1C risk variant affects reward responsiveness in healthy individuals. Transl Psychiatry 4, e461 (2014).

280. Pedram P, Zhai G, Gulliver W, Zhang H, Sun G. Two novel candidate genes identified in adults from the Newfoundland population with addictive tendencies towards food. Appetite 2017 Jan 20 [Epub ahead of print].

281. Bardo MT, Bevins RA. Conditioned place preference: what does it add to our preclinical understanding of drug reward? Psychopharmacology (Berl) 153(1), 31-43 (2000).

282. Degoulet M, Stelly CE, Ahn KC, Morikawa H. L-type Ca(2)(+) channel blockade with antihypertensive medication disrupts VTA synaptic plasticity and drug-associated contextual memory. Mol Psychiatry 21(3), 394-402 (2016).

283. Reimer AR, Martin-Iverson MT. Nimodipine and haloperidol attenuate behavioural sensitization to cocaine but only nimodipine blocks the establishment of conditioned locomotion induced by cocaine. Psychopharmacology (Berl) 113(3-4), 404-410 (1994).

284. Pierce RC, Quick EA, Reeder DC, Morgan ZR, Kalivas PW. Calcium-mediated second messengers modulate the expression of behavioral sensitization to cocaine. J Pharmacol Exp Ther 286(3), 1171-1176 (1998).

285. Pani L, Kuzmin A, Martellotta MC, Gessa GL, Fratta W. The calcium antagonist PN 200-110 inhibits the reinforcing properties of cocaine. Brain Res Bull 26(3), 445-447 (1991).

286. Biala G, Langwinski R. Effects of calcium channel antagonists on the reinforcing properties of morphine, ethanol and cocaine as measured by place conditioning. J Physiol Pharmacol 47(3), 497-502 (1996).

287. Shibasaki M, Kurokawa K, Ohkuma S. Upregulation of L-type $\mathrm{Ca}(\mathrm{v}) 1$ channels in the development of psychological dependence. Synapse 64(6), 440-444 (2010).

288. Kuzmin A, Zvartau E, Gessa GL, Martellotta MC, Fratta W. Calcium antagonists isradipine and nimodipine suppress cocaine and morphine intravenous self-administration in drug-naive mice. Pharmacol Biochem Behav 41(3), 497-500 (1992).

289. Anderson SM, Famous KR, Sadri-Vakili G, et al. CaMKII: a biochemical bridge linking accumbens dopamine and glutamate systems in cocaine seeking. Nat Neurosci 11(3), 344-353 (2008).

290. Zhang Q, Li J-X, Zheng J-W, Liu R-K, Liang J-H. L-type Ca ${ }^{2+}$ channel blockers inhibit the development but not the expression of sensitization to morphine in mice. Eur $J$ Pharmacol 467(1-3), 145-150 (2003).

291. Kuzmin A, Patkina N, Pchelintsev M, Zvartau E. Isradipine is able to separate morphine-induced analgesia and place conditioning. Brain Res 593(2), 221-225 (1992).

292. Michaluk J, Karolewicz B, Antkiewicz-Michaluk L, Vetulani J. Effects of various $\mathrm{Ca}^{2+}$ channel antagonists on morphine analgesia, tolerance and dependence, and on blood pressure in the rat. Eur J Pharmacol, 352(2-3), 189-197 (1998).

293. Tokuyama S, Feng Y, Wakabayashi H, Ho IK. Ca2+ channel blocker, diltiazem, prevents physical dependence and the enhancement of protein kinase C activity by opioid infusion in rats. Eur $J$ Pharmacol 279(1), 93-98 (1995).

294. Tokuyama S, Ho IK. Inhibitory effects of diltiazem, an L-type $\mathrm{Ca}^{2+}$ channel blocker, on naloxone-increased glutamate levels in the locus coeruleus of opioid-dependent rats. Brain Res 722(1-2), 212-216 (1996).

295. Baeyens JM, Esposito E, Ossowska G, Samanin R. Effects of peripheral and central administration of calcium channel blockers in the naloxone-precipitated abstinence syndrome in morphinedependent rats. Eur J Pharmacol 137(1), 9-13 (1987). 
296. Bongianni F, Carla V, Moroni F, Pellegrini-Giampietro DE. Calcium channel inhibitors suppress the morphine-withdrawal syndrome in rats. Br J Pharmacol 88(3), 561-567 (1986).

297. Barrios M, Baeyens JM. Differential effects of L-type calcium channel blockers and stimulants on naloxone-precipitated withdrawal in mice acutely dependent on morphine. Psychopharmacology (Berl) 104(3), 397-403 (1991).

298. Zharkovsky A, Totterman AM, Moisio J, Ahtee L. Concurrent nimodipine attenuates the withdrawal signs and the increase of cerebral dihydropyridine binding after chronic morphine treatment in rats. Naunyn Schmiedebergs Arch Pharmacol 347(5), 483-486 (1993).

299. Vaseghi G, Rabbani M, Hajhashemi V. The effect of nimodipine on memory impairment during spontaneous morphine withdrawal in mice: Corticosterone interaction. Eur J Pharmacol 695(1-3), 83-87 (2012)

300. Vitcheva V, Mitcheva M. Effects of nifedipine on behavioral and biochemical parameters in rats after multiple morphine administration. Methods Find Exp Clin Pharmacol 26(8), 631-634 (2004).

301. Engel JA, Fahlke C, Hulthe P, et al. Biochemical and behavioral evidence for an interaction between ethanol and calcium channel antagonists. J Neural Transm 74(3), 181-193 (1988).

302. Rezvani AH, Janowsky DS. Decreased alcohol consumption by verapamil in alcohol preferring rats. Prog Neuropsychopharmacol Biol Psychiatry 14(4), 623-631 (1990).

303. Fadda F, Garau B, Colombo G, Gessa GL. Isradipine and other calcium channel antagonists attenuate ethanol consumption in ethanol-preferring rats. Alcohol Clin Exp Res 16(3), 449-452 (1992).

304. De Beun R, Schneider R, Klein A, Lohmann A, De Vry J. Effects of nimodipine and other calcium channel antagonists in alcoholpreferring AA rats. Alcohol 13(3), 263-271 (1996).

305. Green-Jordan K, Grant KA. Modulation of the ethanol-like discriminative stimulus effects of diazepam and phencyclidine by Ltype voltage-gated calcium-channel ligands in rats. Psychopharmacology (Berl) 149(1), 84-92 (2000).

306. Holt JD, Watson WP, Little HJ. Studies on a model of long term alcohol drinking. Behav Brain Res 123(2), 193-200 (2001).

307. Balino P, Pastor R, Aragon CM. Participation of L-type calcium channels in ethanol-induced behavioral stimulation and motor incoordination: effects of diltiazem and verapamil. Behav Brain Res 209(2), 196-204 (2010)

308. White JM, Smith AM. Modification of the behavioural effects of ethanol by nifedipine. Alcohol Alcohol 27(2), 137-141 (1992).

309. Czarnecka E, Kubik-Bogucka E. Effects of calcium antagonists on central actions of ethanol: comparative studies with nifedipine, verapamil and cinnarizine. Alcohol Alcohol 28(6), 649-655 (1993).

310. Whittington MA, Dolin SJ, Patch TL, Siarey RJ, Butterworth AR, Little HJ. Chronic dihydropyridine treatment can reverse the behavioural consequences of and prevent adaptations to, chronic ethanol treatment. Br J Pharmacol 103(3), 1669-1676 (1991).

311. Gatch MB. Nitrendipine blocks the nociceptive effects of chronically administered ethanol. Alcohol Clin Exp Res 26(8), 11811187 (2002)

312. Rossetti ZL, Isola D, De Vry J, Fadda F. Effects of nimodipine on extracellular dopamine levels in the rat nucleus accumbens in ethanol withdrawal. Neuropharmacology 38(9), 1361-1369 (1999).

313. Veatch LM, Gonzalez LP. Nifedipine alleviates alterations in hippocampal kindling after repeated ethanol withdrawal. Alcohol Clin Exp Res 24(4), 484-491 (2000).

314. N'Gouemo P. Altered voltage-gated calcium channels in rat inferior colliculus neurons contribute to alcohol withdrawal seizures. Eur Neuropsychopharmacol 25(8), 1342-1352 (2015).

315. Hart C, Kisro NA, Robinson SL, Ksir C. Effects of the calcium channel blocker nimodipine on nicotine-induced locomotion in rats. Psychopharmacology (Berl) 128(4), 359-361 (1996).
316. Biala G. Calcium channel antagonists suppress nicotine-induced place preference and locomotor sensitization in rodents. Pol $J$ Pharmacol 55(3), 327-335 (2003).

317. Biala G, Weglinska B. Blockade of the expression of mecamylamineprecipitated nicotine withdrawal by calcium channel antagonists. Pharmacol Res 51(5), 483-488 (2005).

318. Biala G, Budzynska B. Reinstatement of nicotine-conditioned place preference by drug priming: effects of calcium channel antagonists. Eur J Pharmacol 537(1-3), 85-93 (2006).

319. Jackson KJ, Damaj MI. L-type calcium channels and calcium calmodulin-dependent kinase II differentially mediate behaviors associated with nicotine withdrawal in mice. $J$ Pharmacol Exp Ther 330(1), 152-161 (2009).

320. Robinson TE, Berridge KC. The neural basis of drug craving: an incentive-sensitization theory of addiction. Brain Res Brain Res Rev 18(3), 247-291 (1993).

321. Pierce RC, Kalivas PW. A circuitry model of the expression of behavioral sensitization to amphetamine-like psychostimulants. Brain Res Brain Res Rev 25(2), 192-216 (1997).

322. Vanderschuren LJ, Pierce RC. Sensitization processes in drug addiction. Curr Top Behav Neurosci 3, 179-195 (2010).

323. Stewart J. Review. Psychological and neural mechanisms of relapse. Philos Trans R Soc Lond B Biol Sci 363(1507), 3147-3158 (2008).

324. Nunes EJ, Hughley SM, Small KM, Rajadhyaksha AM, Addy NA. Ventral tegmental area L-type calcium channels mediate cue-induced cocaine seeking and dopamine release during early withdrawal. Program No. 351.05/FFF18, San Diego, CA(Society for Neuroscience), Online (2016).

325. Schierberl K, Hao J, Tropea TF, et al. Cav1.2 L-type $\mathrm{Ca}^{2+}$ channels mediate cocaine-induced GluA1 trafficking in the nucleus accumbens, a long-term adaptation dependent on ventral tegmental area Ca(v)1.3 channels. J Neurosci 31(38), 13562-13575 (2011).

326. Terrillion CE, Dao DT, Cachope R, et al. Reduced levels of Cacna1c attenuate mesolimbic dopamine system function. Genes Brain Behav 2017 Feb 10 [Epub ahead of print].

327. Liu Y, Harding M, Pittman A, et al. Cav1.2 and Cav1.3 L-type calcium channels regulate dopaminergic firing activity in the mouse ventral tegmental area. J Neurophysiol 112(5), 1119-1130 (2014).

328. Wolf ME. Synaptic mechanisms underlying persistent cocaine craving. Nat Rev Neurosci 17(6), 351-365 (2016).

329. Enck RE. Understanding tolerance, physical dependence and addiction in the use of opioid analgesics. Am J Hosp Palliat Care 8(1), 9-11 (1991).

330. Blasig J, Herz A, Reinhold K, Zieglgansberger S. Development of physical dependence on morphine in respect to time and dosage and quantification of the precipitated withdrawal syndrome in rats. Psychopharmacologia 33(1), 19-38 (1973).

331. Wei E, Loh HH, Way EL. Quantitative aspects of precipitated abstinence in morphine-dependent rats. $J$ Pharmacol Exp Ther 184(2), 398-403 (1973).

332. Shibasaki M, Kurokawa K, Mizuno K, Ohkuma S. Up-regulation of $\mathrm{Ca}(\mathrm{v}) 1.2$ subunit via facilitating trafficking induced by Vps34 on morphine-induced place preference in mice. Eur J Pharmacol 651(1-3), 137-145 (2011).

333. Haller VL, Bernstein MA, Welch SP. Chronic morphine treatment decreases the Cav1.3 subunit of the L-type calcium channel. Eur $J$ Pharmacol 578(2-3), 101-107 (2008).

334. Roberto M, Gilpin NW, Siggins GR. The central amygdala and alcohol: role of gamma-aminobutyric acid, glutamate, and neuropeptides. Cold Spring Harb Perspect Med 2(12), a012195 (2012).

335. Silberman Y, Winder DG. Ethanol and corticotropin releasing factor receptor modulation of central amygdala neurocircuitry: an update and future directions. Alcohol 49(3), 179-184 (2015). 
336. Zorumski CF, Mennerick S, Izumi Y. Acute and chronic effects of ethanol on learning-related synaptic plasticity. Alcohol 48(1), 1-17 (2014).

337. N'Gouemo P, Morad M. Ethanol withdrawal seizure susceptibility is associated with upregulation of L- and P-type $\mathrm{Ca}^{2+}$ channel currents in rat inferior colliculus neurons. Neuropharmacology 45(3), 429-437 (2003).

338. Littleton JM, Little HJ, Whittington MA. Effects of dihydropyridine calcium channel antagonists in ethanol withdrawal; doses required, stereospecificity and actions of Bay K 8644. Psychopharmacology (Berl) 100(3), 387-392 (1990).

339. De Biasi M, Dani JA. Reward, addiction, withdrawal to nicotine. Annu Rev Neurosci 34, 105-130 (2011).

340. Katsura M, Mohri Y, Shuto K, et al. Up-regulation of L-type voltage-dependent calcium channels after long term exposure to nicotine in cerebral cortical neurons. J Biol Chem 277(10), 79797988 (2002).

341. Hayashida S, Katsura M, Torigoe F, Tsujimura A, Ohkuma S. Increased expression of L-type high voltage-gated calcium channel alpha1 and alpha2/delta subunits in mouse brain after chronic nicotine administration. Brain Res Mol Brain Res 135(1-2), 280284 (2005)

342. Malin DH, Lake JR, Carter VA, et al. The nicotinic antagonist mecamylamine precipitates nicotine abstinence syndrome in the rat. Psychopharmacology (Berl) 115(1-2), 180-184 (1994).

343. Malin DH. Nicotine dependence: studies with a laboratory model. Pharmacol Biochem Behav 70(4), 551-559 (2001).

344. Post RM, Kalivas P. Bipolar disorder and substance misuse: pathological and therapeutic implications of their comorbidity and cross-sensitisation. Br J Psychiatry 202(3), 172-176 (2013).

345. Lüthi A, Lüscher C. Pathological circuit function underlying addiction and anxiety disorders. Nat Neurosci 17(12), 1635-1643 (2014).

346. Nestler EJ, Carlezon WA, Jr. The mesolimbic dopamine reward circuit in depression. Biol Psychiatry 59(12), 1151-1159 (2006).

347. Russo SJ, Nestler EJ. The brain reward circuitry in mood disorders. Nat Rev Neurosci 14(9), 609-625 (2013).

348. Sun H, Martin JA, Werner CT, et al. BAZ1B in nucleus accumbens regulates reward-related behaviors in response to distinct emotional stimuli. J Neurosci 36(14), 3954-3961 (2016).

349. Khibnik LA, Beaumont M, Doyle M, et al. Stress and cocaine trigger divergent and cell type-specific regulation of synaptic transmission at single spines in nucleus accumbens. Biol Psychiatry 79(11), 898-905 (2016).

350. Lobo MK, Zaman S, Damez-Werno DM, et al. DeltaFosB induction in striatal medium spiny neuron subtypes in response to chronic pharmacological, emotional, and optogenetic stimuli. $J$ Neurosci 33(47), 18381-18395 (2013).

351. Covington HE, 3rd, Maze I, Sun H, et al. A role for repressive histone methylation in cocaine-induced vulnerability to stress. Neuron 71(4), 656-670 (2011).

352. LaPlant Q, Vialou V, Covington HE, 3rd et al. Dnmt3a regulates emotional behavior and spine plasticity in the nucleus accumbens. Nat Neurosci 13(9), 1137-1143 (2010).

353. Chaudhury D, Walsh JJ, Friedman AK, et al. Rapid regulation of depression-related behaviours by control of midbrain dopamine neurons. Nature 493(7433), 532-536 (2013).
354. Tye KM, Mirzabekov JJ, Warden MR, et al. Dopamine neurons modulate neural encoding and expression of depression-related behaviour. Nature 493(7433), 537-541 (2013).

355. Walsh JJ, Han MH. The heterogeneity of ventral tegmental area neurons: Projection functions in a mood-related context. Neuroscience 282, 101-108 (2014)

356. Gunaydin LA, Grosenick L, Finkelstein JC, et al. Natural neural projection dynamics underlying social behavior. Cell 157(7), 1535-1551 (2014).

357. Covey DP, Roitman MF, Garris PA. Illicit dopamine transients: reconciling actions of abused drugs. Trends Neurosci 37(4), 200210 (2014).

358. Nestler EJ. Role of the brain's reward circuitry in depression: transcriptional mechanisms. Int Rev Neurobiol 124, 151-170 (2015).

359. Russo SJ, Dietz DM, Dumitriu D, Morrison JH, Malenka RC, Nestler EJ. The addicted synapse: mechanisms of synaptic and structural plasticity in nucleus accumbens. Trends Neurosci 33(6), 267-276 (2010).

360. Pascoli V, Terrier J, Hiver A, Luscher C. Sufficiency of mesolimbic dopamine neuron stimulation for the progression to addiction. Neuron, 88(5), 1054-1066 (2015).

361. Saddoris MP, Sugam JA, Cacciapaglia F, Carelli RM. Rapid dopamine dynamics in the accumbens core and shell: learning and action. Front Biosci 5, 273-288 (2013).

362. Goffer Y, Xu D, Eberle SE, et al. Calcium-permeable AMPA receptors in the nucleus accumbens regulate depression-like behaviors in the chronic neuropathic pain state. J Neurosci 33(48), 19034-19044 (2013).

363. Lim BK, Huang KW, Grueter BA, Rothwell PE, Malenka RC. Anhedonia requires MC4R-mediated synaptic adaptations in nucleus accumbens. Nature 487(7406), 183-189 (2012).

364. Vialou V, Robison AJ, Laplant QC, et al. DeltaFosB in brain reward circuits mediates resilience to stress and antidepressant responses. Nat Neurosci 13(6), 745-752 (2010).

365. Araki R, Ago Y, Hasebe S, et al. Involvement of prefrontal AMPA receptors in encounter stimulation-induced hyperactivity in isolation-reared mice. Int $J$ Neuropsychopharmacol 17(6), 883893 (2014).

366. Wook Koo J, Labonte B, Engmann O, et al. Essential role of mesolimbic brain-derived neurotrophic factor in chronic social stress-induced depressive behaviors. Biol Psychiatry 80(6), 469478 (2016).

367. Lobo MK, Covington HE, 3rd, Chaudhury D, et al. Cell typespecific loss of BDNF signaling mimics optogenetic control of cocaine reward. Science 330(6002), 385-390 (2010).

368. Le Moine C, Normand E, Bloch B. Phenotypical characterization of the rat striatal neurons expressing the D1 dopamine receptor gene. Proc Natl Acad Sci U S A 88(10), 4205-4209 (1991).

369. Lu XY, Ghasemzadeh MB, Kalivas PW. Expression of D1 receptor, D2 receptor, substance $\mathrm{P}$ and enkephalin messenger RNAs in the neurons projecting from the nucleus accumbens. Neuroscience 82(3), 767-780 (1998).

370. Lohmann C. Calcium signaling and the development of specific neuronal connections. Prog Brain Res 175, 443-452 (2009).

371. Ramocki MB, Zoghbi HY. Failure of neuronal homeostasis results in common neuropsychiatric phenotypes. Nature 455(7215), 912918 (2008). 